OAK RIDGE

ORNL/TM-2002/116

NATIONAL LABORATORY

MANAGED BY UT-BATTELLE

FOR THE DEPARTMENT OF ENERGY

\title{
Caustic-Side Solvent Extraction: Extended Equilibrium Modeling of Cesium and Potassium Distribution Behavior
}

May 2002

Prepared by Lætitia H. Delmau Debbie A. Bostick Tamara J. Haverlock Bruce A. Moyer

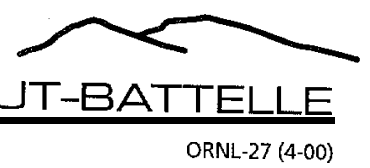




\section{DOCUMENT AVAILABILITY}

Reports produced after January 1, 1996, are generally available free via the U.S. Department of Energy (DOE) Information Bridge:

Web site: http://www.osti.gov/bridge

Reports produced before January 1, 1996, may be purchased by members of the public from the following source:

National Technical Information Service

5285 Port Royal Road

Springfield, VA 22161

Telephone: $703-605-6000(1-800-553-6847)$

TDD: 703-487-4639

Fax: 703-605-6900

E-mail: info@ntis.fedworld.gov

Web site: http://www.ntis.gov/support/ordernowabout.htm

Reports are available to DOE employees, DOE contractors, Energy Technology Data Exchange (ETDE) representatives, and International Nuclear Information Syslem (INIS) representatives from the following source:

Office of Scientific and Technical Information

P.O. Box 62

Oak Ridge, TN 37831

Telephone: 865-576-8401

Fax: $865-576-5728$

E-mail: reports@adonis.osti.gov

Web site: http://www.osti.gov/contact.htm

This report was prepared as an account of work sponsored by an agency of the United States Government. Neither the United States government nor any agency thereof, nor any of their employees, makes any warranty, express or implied, or assumes any legal liability or responsibility for the accuracy, completeness, or usefulness of any information, apparatus, product, or process disclosed, or represents that its use would not infringe privately owned rights. Reference herein to any specific commercial product, process, or senvice by trade name, trademark, manufacturer, or otherwise, does not necessarily constitute or imply its endorsement, recommendation, or favoring by the United States Government or any agency thereof. The views and opinions of authors expressed herein do not necessarily state Or reflect those of the United States Government or any agency thereof. 
ORNL/TM-2002-116

\title{
CAUSTIC-SIDE SOLVENT EXTRACTION: EXTENDED EQUILIBRIUM MODELING OF CESIUM AND POTASSIUM DISTRIBUTION BEHAVIOR
}

Lætitia H. Delmau, Debbie A. Bostick, Tamara J. Haverlock, and Bruce A. Moyer

Date Published: May 2002

\author{
Prepared by \\ OAKRIDGENATIONALLABORATORY \\ P.O. Box 2008 \\ Oak Ridge, Tennessee 37831-6285 \\ managed by \\ UT-B attelle, LLC \\ for the \\ U.S. DEPARTMENT OF ENERGY \\ under contract DE-AC05-00OR22725
}


Page intentionally left blank. 


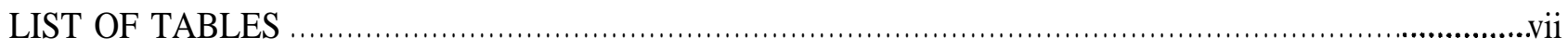

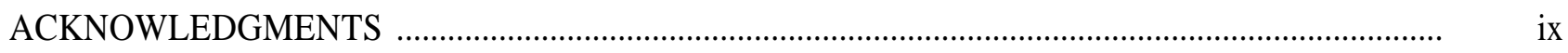

ABSTRACT $\quad$.

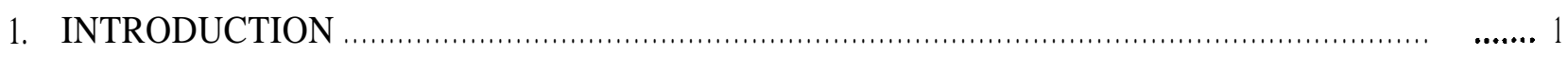

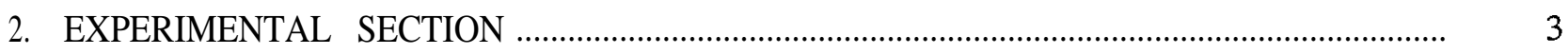

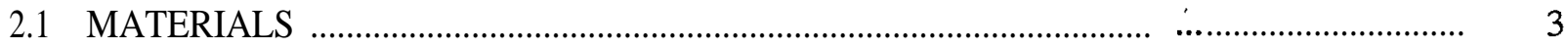

2.2 GENERAL CONTACTINGAND COUNTING PROCEDURE ……................................... 3

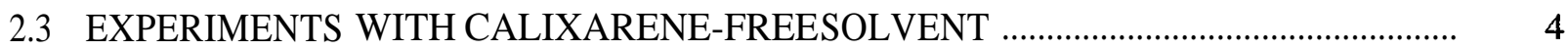

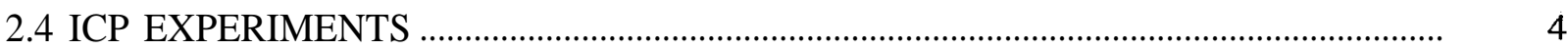

3. MODELINGCONCEPTS AND PROGRAM SXFIT ............................................................ 5

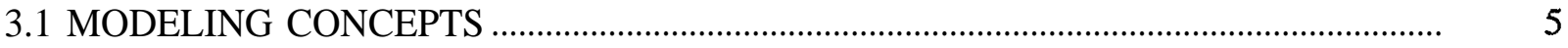

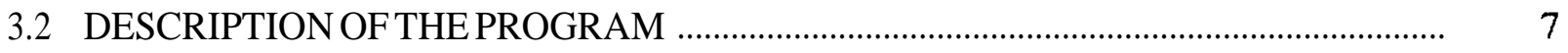

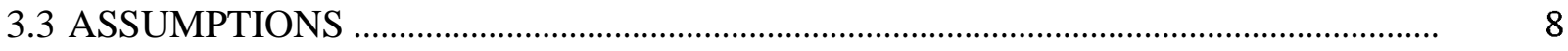

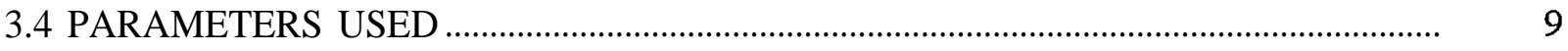

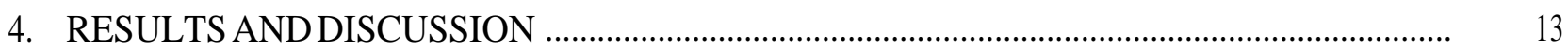

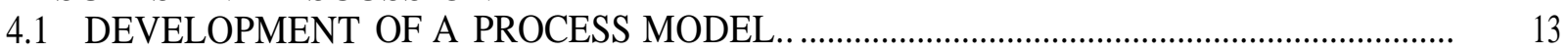

4.1.1 TESTS USING TANK SIMULANTS.. …….................................................... 14

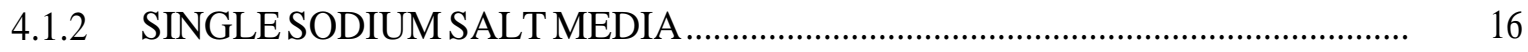

4.1.3 SYSTEMS CONTAINING A MIXTURE OF TWO SODIUM SALTS................... 20

4.1.4 SYSTEMS CONTAINING A MIXTURE OF THREE OR FOUR SODIUM SALTS 23

4.1.5 CARBONATE, SULFATE, AND FLUORIDE MEDIA …..................................... 26

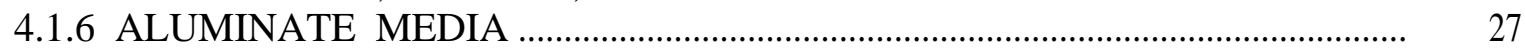

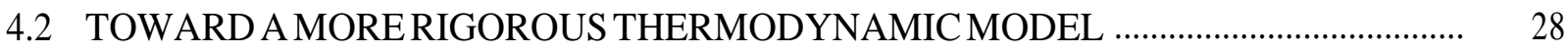

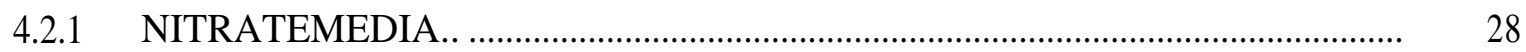

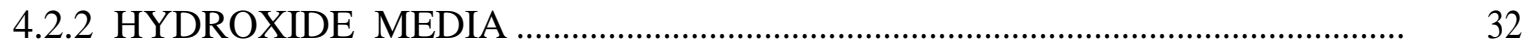

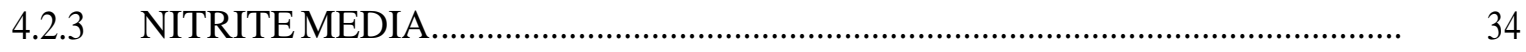

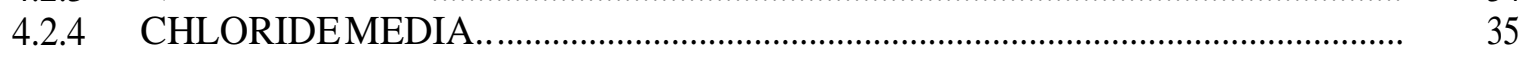

4.2.5 ATTEMPT TO MODEL SALT MIXTURES ……............................................... 36

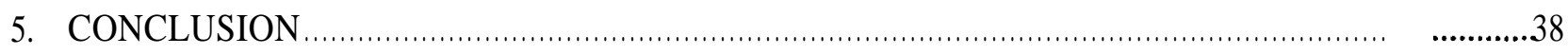

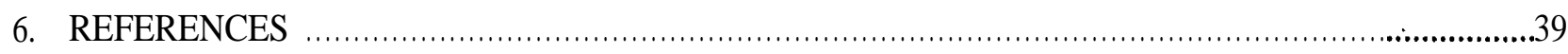

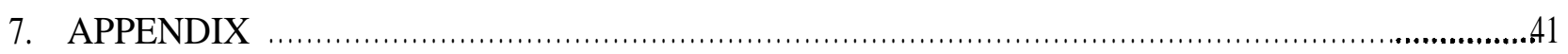




\section{Page intentionally left blank.}


1 Modeling of cesium and potassium distribution ratios for the nitrate media.. ….............................. 17

2 Modeling of cesium and potassium distribution ratios for the hydroxide media............................. 18

3 Modeling of cesium and potassium distribution ratios for the nitrite media $\ldots \ldots \ldots \ldots \ldots \ldots \ldots \ldots \ldots \ldots \ldots . . \ldots$

4 Modeling of cesium and potassium distribution ratios for the chloride media . . . . . . . . . . . . . . . . . 20

5 Modeling of cesium distribution ratios for nitrate-based systems ...................................... 21

6 Modeling of cesium distribution ratios for chloride-based systems …............................... 22

7 Modeling of cesium distribution ratios for nitrite-based system ...................................... 23

8 Modeling of cesium distribution ratios for three sodium salts data sets ...* .................................. 24

9 Modeling of cesium distribution ratios for four sodium salts data set …............................. 25

10 Modeling of cesium distribution ratios for fluoride, carbonate, and sulfate media ................... 26

11 Modeling of potassium and sodium distribution ratios for nitrate media........................................ 30

12 Modeling of cesium distribution ratios for nitrate media ................................................. 31

13 Extraction of sodium (with and without calixarene) and comparison between the nitrate and

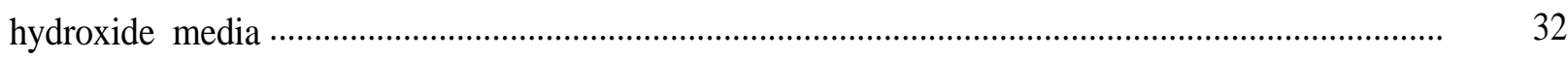

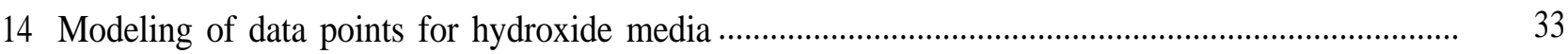

15 Modeling of cesium and potassium distribution ratios for nitrite media......................................... 34

16 Modeling of cesium and potassium distribution ratios for chloride media . . . . . . . . . . . . . . . . . . . . 36 
Page intentionally left blank. 


\section{LIST OF TABLES}

Table

Page

1 Molecular weights and nonaqueous molar volumes of the constituents .............................. 10

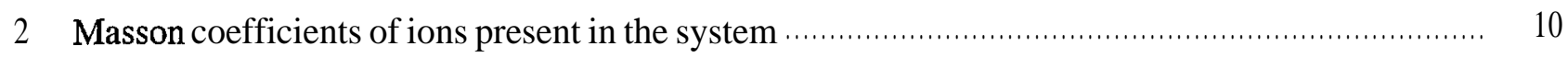

3 Pitzer parameters for the interactions between cations and anions ….............................. 11

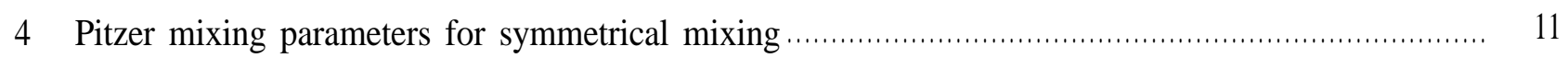

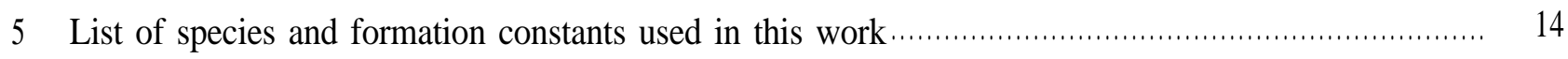

6 Comparison of measured and predicted distribution ratios for tank simulants …....................... 15

7 Formation constant for the model including fluoride, sulfate, and carbonate media . . . . . . . . . . . 27

8 Species and formation constants for the model derived for nitrate data......................................... 29

9 Species and formation constants for the model derived for hydroxide data ................................... 33

10 Species and formation constants for the model derived for nitrite data ….............................. 35

11 Species and formation'constants for the model derived for chloride data …............................ 35 
Page intentionally left blank. 


\section{ACKNOW LEDGM ENTS}

The authors would like to express their deepest gratitude to Charles F. Baes, Jr for his constant help and advice regarding the program SXFIT. 
Page intentionally left blank. 


\section{ABSTRACT}

An extension of the model developed in FY01 for predicting equilibrium distribution ratios in the Caustic-Side Solvent Extraction (CSSX) process is presented here. Motivation for extending the model arose from the need to predict extraction performance of the recently optimized solvent composition and the desire to include additional waste components. This model involves the extraction of cesium and potassium from different cesium, potassium, and sodium media over a large range of concentrations. Those different media include a large variety of anions such as nitrate, hydroxide, nitrite, chloride, fluoride, sulfate, and carbonate. The model was defined based on several hundreds of experimental data points and predicted satisfactorily the cesium extraction from five different SRS waste simulants. This process model encompassed almost exclusively 1:1:1 metal:anion:ligand species. Fluoride, sulfate, and carbonate species were found to be very little extractable, and their main impact is reflected through their activity effects. This model gave a very good cesium and potassium extraction prediction from sodium salts, which is what is needed when trying to predict the behavior from actual waste. However, the extraction from potassium or cesium salts, and the extraction of sodium could be improved, and some additional effort was devoted to improve the thermodynamic rigor of the model. Toward this end, more detailed anion-specific models were developed based on the cesium, potassium, and sodium distribution ratios obtained with simple systems containing single anions, but it has not yet proven possible to combine those models to obtain better predictions than provided by the process model.

\section{INTRODUCTION}

The solvent extraction process chosen by U.S. Department of Energy for cesium removal from the alkaline high-level waste stored at the Savannah River Site (SRS) is being investigated with respect to the behavior of system components under different conditions with the ultimate goal of being able to predict cesium and potassium distribution values from characterized actual waste [1]. A solid understanding of the process is in part demonstrable by establishing a model that predicts the extraction of potassium and cesium based on the major components of the waste (or simulant). The ability to predict distribution behavior provides greater confidence in the robustness of the process overall. In addition, given the knowledge of the composition of any particular feed, a reliable model yields an immediate estimate of expected flowsheet performance for process control and comparison with process data. The model that needs to be developed permits the correlation of experimental data with one mathematical set of equations. These equations, derived from thermodynamic equilibria, have a given number of parameters. Some parameters are tabulated in the literature (particularly those related to activity effects in 
the system); others need to be defined and calculated during model development. After species assumed to be formed in the organic phase upon extraction are defined, their associated formation constants are iteratively refined so that the experimental and calculated data are in good agreement. Once the entire set of parameters is defined and held constant, the corresponding model can then predict the extraction behavior over a wide range of conditions for which the parameters are valid. The scope of this modeling study was directed toward an extension of the model established in FY01[2]. That model was developed using the FY01 baseline solvent, whose composition was subsequently optimized at the beginning of FY02 [3]. In addition to the change of solvent, it was desirable to include anions other than nitrate, hydroxide, nitrite, and chloride (already present in the FY01 model) in this extended model. Aluminate was chosen because of its relatively large concentration in the waste. Sulfate, carbonate, and fluoride were recommended by SRS personnel. All parameters needed for a process-oriented model were determined using the experimental results obtained for the extraction of cesium and potassium from single sodium salts or mixtures of sodium salts. Tests of the model were performed by comparing predicted and experimental cesium distribution ratios for the optimized solvent and simplified tank simulants of five different tanks. Chemical analyses of the tanks provided the concentrations of sodium, potassium, cesium, nitrate, and free hydroxide, and the total concentration of sodium ion in the simulants was as high as 5.6 M. Satisfactory agreement was found between predicted and experimental results. In that the model makes simplifying assumptions, additional effort was also directed toward development of a more rigorous alternative model. 


\section{EXPERIMENTAL PROGRAM}

\subsection{ATERIALS}

Stock solutions of $\mathrm{NaNO}_{3}, \mathrm{NaNO}_{2}, \mathrm{NaCl}$, and $\mathrm{NaOH}$ were prepared directly from ACS (American Chemical Society)-grade reagents; concentrations lower than $0.1 \mathrm{M}$ were prepared as a dilution of the stock. Sodium hydroxide (EM Science, Lot No. 126754-115657) was prepared by dissolving weighed quantities of $\mathrm{NaOH}$ pellets in nanopure water. Sodium chloride was received from EM Science (EM Sci.), Lot No. 33131325; $\mathrm{NaNO}_{2}$ was received from J. T. Baker, Lot No. L32624; $\mathrm{NaNO}_{3}$ was received from EM Sci., Lot 40074121, as reagent grade crystal. Cesium chloride, 99.999\% purity, was purchased from International Biotechnologies, Inc. (Lot No. OF0751). Cesium fluoride, 99.99\% purity was supplied by Aldrich Chemical Co. (Aldrich). The nitrate (Lot No. 07319DU), hydroxide (Lot No. 0643KU), carbonate (Lot No. ES 04403BS), and sulfate (Lot No. 02922M) salts of cesium were purchased from Aldrich. Potassium nitrate, 99.99\% purity, was received from Aldrich (Lot No. 1242AO); the chloride salt was supplied by EM Science, Lot No. 6116. Potassium nitrite solutions were derived from reagent-grade salt manufactured by Mallinkrodt Chemical Works (Mallinkrodt), Lot KHXH. Pellets of potassium hydroxide, with a stated moisture content of less than $14 \%$, were supplied by Fluka Biochemika. Sodium concentrations were prepared at levels of $0.1 \mathrm{M}$ through $7 \mathrm{M}$. Cesium and potassium salts were added at $0.5 \mathrm{mM}$ and $60 \mathrm{mM}$, respectively, directly to the sodium salt solutions, effecting a slight dilution of the initial sodium in solution. Extractions of cesium from cesium salt solutions were performed at cesium concentrations of $0.001 \mathrm{M}$ through 2.0 M. Binary salt solutions at anion ratios of $0,0.10,0.25,0.50,0.75,0.90$, and 1.0 and total sodium concentration of $5 \mathrm{M}$ were also prepared with the complimentary cesium salt added at $0.5 \mathrm{mM}$, as well as with and without the potassium salt at $60 \mathrm{mM}$. The hexahydrate form of aluminum chloride (Mallinkrodt, Lot No. 3148KVDH) was dissolved directly in $5 \mathrm{M} \mathrm{NaOH}$ to perform contact studies for cesium extraction from sodium-aluminumbearing solutions. The organic phase consisted of 0.007 M BOBCalixC6 (Lot No. 00714MKC-004); 0.750 M Cs-7SB modifier (Lot No. B00894-64DM); 0.003 M trioctylamine (Lot No. B00894-86); and Isoparß L (Lot No. 03081001-6-2) prepared by P. V. Bonnesen and K. Anderson at ORNL on December 3, 2001. The radiotracers ${ }^{22} \mathrm{Na}$ and ${ }^{137} \mathrm{Cs}$ were obtained from Isotope Products, Burbank, CA.

\subsection{GENERAL SOLVENT EXTRACTION AND COUNTING PROCEDURE}

Capped micro-tubes were mounted by clips on a disk that was rotated in a constant-temperature air box at $25.0 \pm 0.5^{\circ} \mathrm{C}$ for 30 minutes. After the contacting period, the tubes were centrifuged for 3 
minutes at $3000 \mathrm{RPM}$ and $25^{\circ} \mathrm{C}$ in a Beckman Coulter ${ }^{\mathrm{TM}}$ Allegra 6R temperature-controlled centrifuge. A $300 \mu \mathrm{L}$ aliquot of each phase was subsampled and counted using a Packard Cobra II Auto-Gamma counter. Aqueous phases were counted for a period of 5 minutes; organic phases were counted for 10 minutes using a window of 580-750 $\mathrm{keV}$.

\subsection{EXPERIMENTS WITH CALIXARENE-FREE SOLVENT}

In this experiment cesium extraction as a function of the solvent/modifier/trioctylamine (TOA) system was investigated. A contacting experiment was carried out, using an O/A volume ratio of unity. Four-tenths milliliters of washed calix-free CSSX solvent was contacted at $25^{\circ} \mathrm{C}$ with $0.4 \mathrm{~mL}$ of an aqueous phase consisting of $0.5 \mathrm{mM} \mathrm{CsOH}$ and variable concentrations of $\mathrm{CsOH}(0.001,0.003,0.01$, $0.03,0.1,0.3$, and $1.0 \mathrm{M})$.

The calix-free organic phase was prepared by adding Cs-7SB modifier (Lot no. B000894-64DM) at $0.75 \mathrm{M}$, and TOA (Lot No. B000894-86) at 0.003 M to Isopar® L (Lot no. 03081001-6-2). This solvent was then washed in Teflon@ FEP labware using an O/A volume ratio of unity, twice with $0.1 \mathrm{M}$ $\mathrm{NaOH}$ and $50 \mathrm{mM} \mathrm{HNO}_{3}$, and three times with deionized water. The aqueous phases were made by appropriately diluting $50 \% \mathrm{w} / \mathrm{w}$ solution of $\mathrm{CsOH}$ in nanopure water. ${ }^{137} \mathrm{CsCl}$ tracer was introduced at 1 $\mu \mathrm{Ci} / \mathrm{mL}$ in the aqueous phase. The contacts were carried out for a period of 30 minutes in $2.0 \mathrm{~mL}$ Eppendorf flip-top tubes.

\subsection{ICP EXPERIMENTS}

The analyses of potassium and sodium ion extracted from variable potassium or from variable sodium nitrate solutions was carried out using inductively coupled argon plasma optical emission spectroscopy (ICAP-OES, IRIS model, Thermo Jarrell Ash). The detection limits for the two ions were $2.2 \mathrm{E}-06 \mathrm{M}$ and $1 \mathrm{E}-05 \mathrm{M}$ for potassium and sodium respectively.

All extractions were carried out in equal volumes using polypropylene plastic vials. Equilibrations were for $1-2$ hours at $25 \pm 0.1$ "C. All samples were centrifuged. Stripping was effected by diluting the organic phase with an equal volume of 1,3-diisopropylbenzene then contacting the organic volume with $2 \%$ nitric acid (UltrexII) at an O/A ratio of 0.20 . For potassium from sodium nitrate determinations, potassium was held constant at $60 \mathrm{mM}$ in $\mathrm{NaNO}_{3}$ ranging from 0.01 to $5.6 \mathrm{M}$ as solubility allowed. Potassium alone was extracted from $\mathrm{KNO}_{3}$ ranging from 0.01 to $7.0 \mathrm{M}$. 


\subsection{MODELING CONCEPTS}

A model is a conceptual or mathematical tool used for a given system to predict the behavior of this system based on a set of initial conditions. The conditions in the present case are experimental variables and include concentrations of system components and O/A ratios. On a more mathematical basis, a model consists of a set of equations that are postulated. In addition to variables, the equations include constants, which may be equilibrium constants or other empirical quantities. These are called parameters. Once these are known, the set of equations may be numerically or analytically solved for any given initial state of the system to predict its equilibrium state. It is the object of model development to define an appropriate set of equations and to determine the optimum values of the parameters to successfully fit the available experimental data. This is sometimes called "fitting" the data. Solventextraction data most often involve distribution ratios for selected extractable species (e.g., cesium or potassium cations) or their corresponding concentrations in both phases. A model so developed may then be used to predict distribution ratios for any new set of initial conditions.

The success of a model may be judged according to how well it fulfills the purpose of the model. Normally, one wishes to correlate data within a desired degree of precision, typically within experimental precision. For process purposes, simplicity and approachability are valued, and thus, simplifying assumptions that do not compromise the fitting precision are welcome. On the other hand, some degree of fidelity to' thermodynamic principles is desirable for flexibility in extending the model's applicability to new conditions or for more complete prediction of system behavior.

The model developed herein is based on mass-action principles and thus entails equilibria corresponding to postulated organic-phase species. Formation constants are associated with these species, mass balances are necessary for each component, and activity coefficients are assigned to each species in each phase. Once the species have been postulated, the essence of the model is defined. Generic equations associated with any postulated set of species can be expressed as shown below.

First of all, the generic equilibria for the extraction of monovalent cations and anions by an extractant $\mathrm{B}$ can be written as

$$
\mathrm{M}_{\mathrm{i}}^{+}+\mathrm{X}_{\mathrm{j}}^{-}+\overline{\mathrm{B}} \stackrel{\mathrm{K}_{\mathrm{ij}}}{\longrightarrow} \overline{\mathrm{M}_{\mathrm{i}} \mathrm{X}_{\mathrm{j}} \mathrm{B}}
$$

where $\mathrm{M}_{\mathrm{i}, 1 \leq i \leq m}^{+}$and $\mathrm{X}_{\mathrm{j}, 1 \leq j \leq \mathrm{s} n}$ represent all the cations and all the anions in the system. For the simplicity of this example, it will be assumed that ionic charges are univalent and only 1:1:1 metal:anion:ligand species 
are formed. In the systems that will be considered in the next chapter to determine the species to include in a process model, combinations of 3 cations $(1 \leq \mathrm{i} \leq 3)$ and 4 anions $\quad(1 \leq \mathrm{j} \leq 4)$ will have to be included. The corresponding formation constants of eq. 1 are

$$
K_{i j}=\frac{a \overline{M_{i} X_{j} B}}{a_{M_{i}^{+}{ }_{X_{j}^{-}} a_{\bar{B}}}}=\frac{\gamma_{\overline{M_{i} X_{j} B}}\left[\overline{M_{i} X_{j} B}\right]}{\gamma_{M_{i}^{+}}\left[M_{i}^{+}\right] \gamma_{X_{j}^{-}}\left[X_{j}^{-}\right] \gamma_{\bar{B}}[\bar{B}]}
$$

This expression of the formation constant introduces activity coefficients into the model. Their calculation can be made different ways, and a subroutine dedicated to these calculations is usually embedded in the computer program based on the activity treatment employed in the model. These derivations will not be addressed, and the reader is referred to standard texts on solution thermodynamics. Mass-balance equations can be written as follows:

$$
\begin{aligned}
& {\left[\mathrm{M}_{\mathrm{i}}^{+}\right]+\sum_{\mathrm{j}=1}^{\mathrm{n}}\left[\overline{\mathrm{M}_{\mathrm{i}} \mathrm{X}_{\mathrm{j}} \mathrm{B}}\right]=\left[\mathrm{M}_{\mathrm{i}}^{+}\right]_{\text {init }}} \\
& {\left[\mathrm{X}_{\mathrm{j}}^{-}\right]+\sum_{\mathrm{i}=1}^{\mathrm{m}}\left[\overline{\mathrm{M}_{\mathrm{i}} \mathrm{X}_{\mathrm{j}} \mathrm{B}}\right]=\left[\mathrm{X}_{\mathrm{j}}^{-}\right]_{\text {init }}} \\
& {[\overline{\mathrm{B}}]+\sum_{\mathrm{i}=1 \mathrm{j}=1}^{\mathrm{m}} \sum^{\mathrm{n}}\left[\overline{\mathrm{M}_{\mathrm{i}} \mathrm{X}_{\mathrm{j}} \mathrm{B}}\right]=[\overline{\mathrm{B}}]_{\mathrm{init}}}
\end{aligned}
$$

Equations 2-5 may in principle be solved together with activity-coefficient expressions to give expressions for any equilibrium species concentration in the system. If $\mathrm{M}^{+}=\mathrm{H}^{+}$or $\mathrm{X}=\mathrm{OH}-$, it may be necessary to include the solvolysis expression $\mathrm{K}_{\mathrm{w}}=\mathrm{a}_{\mathrm{H}^{+}} \mathrm{a}_{\mathrm{OH}^{-}} / \mathrm{a}_{\mathrm{H}_{2} \mathrm{O}}$, where $\mathrm{a}$ is the activity of the species denoted by the subscript. As seen in the Appendix, even for the simplest cases, a numerical solution is required by non-linear computer methods. The obtained solution can then be used to calculate experimentally observable quantities (e.g., distribution ratios) that depend on species concentrations, including the concentrations themselves. The experimentally-measured quantity in this work is the distribution coefficient of the cation of interest $\mathbf{M}_{\mathbf{i}}^{+}$:

$$
\mathrm{D}_{\mathrm{M}_{\mathrm{i}}^{+}}=\frac{\left[\overline{\mathrm{M}_{\mathrm{i}}^{+}}\right]_{\mathrm{eq}}}{\left[\mathrm{M}_{\mathrm{i}}^{+}\right]_{\mathrm{eq}}}
$$

Replacing the numerator and denominator by analog expressions depending exclusively on the initial concentrations and the formation constants of the species formed upon extraction in the organic phase gives the dependence of the value of $\mathrm{D}$ vs. the initial conditions. An example of the complete derivation for a system including a neutral ligand, sodium, potassium, cesium, and an anion can be found in the Appendix section.

Determining the set of species formed in the organic phase is an essential aspect of the parameterization of the model. The corresponding mass-balance equations can then be written, and the 
formation constants can be determined based on the experimental data (distribution ratios). The computer program SXFIT is particularly useful in selection of the optimum set of species for the model. Formation constants are then refined to give the best correlation between the experimental and calculated values. A more thorough description is given in the next paragraph. The combination of product species/formation constants, together with physical constants needed to calculate activity coefficients, volume changes, and other quantities, gives all the parameters needed from which equilibrium reactions, mass balances, and physical properties can be written, defining a model ready to predict distribution ratios based on the initial conditions of the system.

\subsection{DESCRIPTION OF THE PROGRAM}

The computer program SXFIT can model extraction data based on the constituents of the systems and the species that are being formed. Although the program's ability to model different kinds of systems is almost limitless, its capability to handle distribution ratios of ions is described here for predicting cesium extraction behavior. Like the preceding codes SXLSQ [4], SXLSQA [5], and SXLSQI [6], SXFIT [7] is a program written in FORTRAN that refines a series of given inputs based on the leastsquares minimization of the difference between the observed and the calculated quantities. The main improvement of SXFIT over SXLSQI is its ability to handle an unlimited number of system components. The program then calls for the parameters that are used to calculate the activity effects occurring in the aqueous phase (Masson and Pitzer coefficients) and the organic phase (Solubility parameters). In addition, molecular weights and nonaqueous molar volumes of the different constituents need to be provided along with the dielectric constant and the solubility parameter of the diluent in the organic phase. All initial concentrations of constituents are entered in a data file. Finally, based on the knowledge of the extraction reactions that occur during the process, a few reasonable species (products of the extraction system) may also be specified together with their initial estimates of formation constants. The program then calculates for each initial condition specified the concentrations of all species at equilibrium and the distribution coefficients of the ion of interest. In an iterative process that minimizes the aggregate difference between the observed and calculated values according to the least-squares criterion, the program will then refine the formation constants of the input species until the best fit is obtained. Of course, this could easily become a simple curve-fitting exercise in which a large number of parameters are used to fit a smaller number of data points. However, the user must ensure that all the species and their relative formation constants are chemically reasonable and that an adequate data set is used. Usually, the preference will be given to a model that contains the lowest number of species for a 
given goodness of fit, represented in the program by the agreement factor. A perfect fit yields an agreement factor of 1 if experimental error has been estimated accurately. A value greater than 1 indicates a poorer fit or an underestimate of the experimental error, while a value between 0 and 1 indicates an overestimate of the experimental error [4].

\subsection{ASSUMPTIONS}

The solvent used in this system comprises $0.007 \mathrm{M}$ calix[4]arene-bis(tert-octylbenzo crown-6) (BOBCalixC6), 0.75 M 1-(2,2,3,3-tetrafluoropropoxy)-3-(4-sec-butylphenoxy)-2-propanol (Cs7-SB modifier), and $0.003 \mathrm{M}$ TOA in Isoparß L. The concentrations of the modifier and of TOA are held constant. The concentration of the modifier is large enough to neglect the amount that is being complexed during the extraction of the cations. Therefore, for simplicity it will not appear in any species of the model. Regarding TOA, we chose not to include it in the model. Its only influence occurs when the aqueous phase contains enough acid to convert TOA into its acidic form, which in turn increases the amount of nitrate in the organic phase. In this work, only two sets of data involved nitric acid, and it was found that TOA did not have any influence on the cesium or potassium distribution ratios. Should a model for the scrub and strip stages be needed, this restriction will need to be removed to properly account for acid balance. Likewise, an accurate accounting of volume and concentration changes would benefit from knowledge of water transferred to and from the solvent; this was also omitted from the present treatment.

In general, activity coefficients of aqueous ions are not close to unity, and these interactions (or . nonideality effects) are modeled in the system using tabulated Pitzer parameters. These tabulated values may have been determined at ionic strengths lower than some of our conditions. The values for the symmetrical mixing (where two salts having either the cation or the anion in common are mixed together) that represent the interaction of two cations with one anion or one cation with two anions are not always available in the literature and are then assumed to be equal to 0. This assumption may not be a problem when modeling data from one given system (one specific anion) as the refined formation constants for the species formed in the organic phase will compensate for those effects. However, when trying to model several sets where anions and cations are varying and mixtures of salts are used, the behavior may not be effectively modeled assuming that the formation constants will incorporate the effects. It may thus be seen that future improvements to the model may be made as new or better Pitzer parameters are reported in the literature. Such model improvements would allow better predictions for a wider range of waste compositions. 


\subsection{PARAMETERS USED}

The program requires a series of input parameters, most of which are available in published handbooks and literature. Those parameters involved in the activity coefficients in the organic and aqueous phases can be refined by the program (Pitzer parameters, solubility parameters). However, for these experiments, the parameters were either calculated prior to any modeling or obtained from referenced sources and kept constant. The only parameters refined during the modeling process itself were the formation constants of the species in the organic phase. All non-refined parameters used for the model are presented in Tables 1 through 4. 
Table 1. M olecular weights and nonaqueous molar volumes of the constituents

\begin{tabular}{|c|c|c|}
\hline Constituent & Formula W eight (g/mol) & Nonaqueous molar volume $\left(\mathbf{c m}^{3} / \mathbf{m o l}\right)^{*}$ \\
\hline $\mathrm{Na}^{+}$ & 22.990 & 10 \\
\hline $\mathrm{K}^{+}$ & 39.098 & 9 \\
\hline cs+ & 132.91 & 21.5 \\
\hline $\mathrm{H}^{+}$ & 1.008 & 0 \\
\hline $\mathrm{NO}_{3}{ }^{\circ}$ & 62.005 & 29 \\
\hline $\mathrm{Cl}^{-}$ & 35.450 & 18 \\
\hline $\mathrm{NO}_{2}$ & 46.006 & 26 \\
\hline $\mathrm{OH}^{-}$ & 17.008 & 18 \\
\hline $\mathrm{CO}_{3}{ }^{2-}$ & 59.997 & -3.7 \\
\hline $\mathrm{SO}_{4}^{2-}$ & 95.996 & 14.3 \\
\hline $\mathrm{F}$ & 18.998 & -1.0 \\
\hline BOBCalixC6 & 1149.53 & 500 \\
\hline Diluent (Isopar@ L) & 170 & 227 \\
\hline Water & (2) & 18 \\
\hline
\end{tabular}

The values for the constituents presented in all tables are those called by the program and changeable by the users. The molecular weight of water is $18.015 \mathrm{~g} / \mathrm{mol}$. This value is a constant and non-changeable.

Table 2. Masson coefficients [8] of ions present in the system

\begin{tabular}{l|c|c}
\hline Constituent & $\mathbf{V}_{\mathbf{0}}$ & $\mathbf{S v}$ \\
\hline $\mathrm{Na}^{+}$ & -1.3 & 1.203 \\
$\mathrm{~K}^{+}$ & 8.73 & 1.10 \\
$\mathrm{cs}+$ & 21.40 & 1.29 \\
$\mathrm{H}^{+}$ & 0 & 0 \\
$\mathrm{NO}_{3}$ & 29.33 & 0.543 \\
$\mathrm{Cl}^{-}$ & 18.12 & 0.83 \\
$\mathrm{NO}^{+}$ & 26.5 & 2.00 \\
$\mathrm{OH}^{-}$ & -1.04 & 2.32 \\
$\mathrm{CO}_{3}{ }^{2-}$ & -3.7 & 7.30 \\
$\mathrm{SO}_{4}{ }^{2-}$ & 14.3 & 10.50 \\
$\mathrm{~F}$ & -0.85 & 1.35 \\
\hline
\end{tabular}


Table 3. Pitzer parameters [9] for the interactions between cations and anions

\begin{tabular}{l|c|c|c}
\hline Interaction & $\boldsymbol{\beta}_{\mathbf{0}}$ & $\boldsymbol{\beta}_{1}$ & $\mathbf{C}_{\boldsymbol{\Phi}}$ \\
\hline $\mathrm{H}^{+}-\mathrm{NO}_{3}$ & 0.11190 & 0.36860 & 0.002470 \\
$\mathrm{Na}^{+}-\mathrm{NO}_{3}$ & 0.006800 & 0.1783 & -0.000720 \\
$\mathrm{Na}^{+}-\mathrm{Cl}^{-}$ & 0.07650 & 0.26640 & 0.001270 \\
$\mathrm{Na}^{+}-\mathrm{NO}_{2}$ & 0.06410 & 0.10150 & -0.004900 \\
$\mathrm{Na}^{+}-\mathrm{OH}^{-}$ & 0.08640 & 0.25300 & 0.004000 \\
$\mathrm{Na}^{+}-\mathrm{F}^{-}$ & 0.0215 & 0.2107 & 0.000000 \\
$\mathrm{Na}^{+}-\mathrm{SO}_{4}^{2-}$ & 0.01958 & 1.11300 & 0.002487 \\
$\mathrm{Na}^{+}-\mathrm{CO}_{3}^{2-}$ & 0.03623 & 1.50975 & 0.002599 \\
$\mathrm{~K}^{+}-\mathrm{NO}_{3}$ & -0.08160 & 0.04940 & 0.006600 \\
$\mathrm{~K}^{+}-\mathrm{Cl}^{-}$ & 0.04835 & 0.21220 & -0.000840 \\
$\mathrm{~K}^{+}-\mathrm{NO}_{2}$ & 0.01510 & 0.01500 & 0.000700 \\
$\mathrm{~K}^{+}-\mathrm{OH}^{-}$ & 0.12980 & 0.32000 & 0.000410 \\
$\mathrm{Cs}^{+}-\mathrm{NO}_{3}^{-}$ & -0.07580 & -0.06690 & 0.000000 \\
$\mathrm{Cs}^{+}-\mathrm{Cl}^{-}$ & 0.03478 & 0.03974 & -0.000496 \\
$\mathrm{Cs}^{+}-\mathrm{NO}_{2}$ & 0.04270 & 0.06000 & -0.005100 \\
$\mathrm{Cs}^{+}-\mathrm{OH}^{-}$ & 0.15000 & 0.30000 & 0.000000 \\
$\mathrm{Cs}^{+}-\mathrm{F}^{2-}$ & 0.13060 & 0.25700 & -0.00430 \\
$\mathrm{Cs}^{+}-\mathrm{SO}_{4}^{2-}$ & 1.20075 & 0.001456 \\
$\mathrm{Cs}^{+}-\mathrm{CO}_{3}^{2-}$ & 0.07140 & 0.002599 \\
\hline
\end{tabular}

All $\beta_{2}$ values are set to 0 . Parameter $\alpha_{1}=2$, and $\alpha_{2}=0$, since all the interactions are between two monocharged ions.

Table 4. Pitzer mixing parameters [9] for symmetrical mixing

\begin{tabular}{l|c|c}
\hline Interaction & $\mathbf{1 0} \Theta$ & $\mathbf{1 0}$ \\
\hline $\mathrm{Na}^{+}-\mathrm{NO}_{3}^{+}-\mathrm{Cl}^{-}$ & 2.26 & -0.72 \\
$\mathrm{Na}^{+}-\mathrm{Cl}^{+}-\mathrm{OH}^{-}$ & -7.0 & -0.32 \\
$\mathrm{Na}^{+}-\mathrm{K}^{+}-\mathrm{NO}_{3}^{-}$ & -2.13 & 0.09 \\
$\mathrm{~K}^{+}-\mathrm{Cl}^{-+}-\mathrm{OH}^{-}$ & -7.0 & 0.16 \\
$\mathrm{~K}+-\mathrm{Cl}-\mathrm{+}-\mathrm{NO}$, & 2.26 & -0.77 \\
$\mathrm{~K}^{+}-\mathrm{Cs}^{+}-\mathrm{Cl}^{-}$ & -0.37 & -0.06 \\
\hline
\end{tabular}


Regarding the activity coefficients in the organic phase, all the product species were assigned a similar value. The solubility parameter of the diluent (Isoparß L) and the extractant BOBCalixC6 were determined by group-contribution calculations [10]. The calixarene solubility parameter was estimated with the group contributions and determined to be $21 \mathrm{~J}^{1 / 2} \mathrm{~cm}^{-3 / 2}$. All organic species formed in the organic phase were assigned a solubility parameter of $19.8 \mathrm{~J}^{1 / 2} \mathrm{~cm}^{-3 / 2}$, which is also the solubility parameter of the modifier. Previous studies showed that at least one molecule of modifier was included in the complexes, and the solubility parameter is close enough to the value for the calixarene to avoid any major activity effect. Since the modifier itself is not included as a component of the system, the solubility parameter of the mixture of Isoparß $\mathrm{L}$ and modifier is set at $18.8 \mathrm{~J}^{1 / 2} \mathrm{~cm}^{-3 / 2}$ (respective weighing factor applied to their solubility parameters based on their relative proportion in the solvent). While solubility parameters give a more realistic view of the behavior in the organic phase, they do not have a crucial effect on the final results, as the mole fraction of extracted species in the solvent is very small. This hypothesis was verified by assuming ideality in the organic phase. The formation constants of all organic product species varied minimally (within the error associated with the Log, $\mathrm{K}$ value, see Table 5). Assuming ideality in the organic phase is therefore validated for the process model; however, solubility parameters are provided for informtion purposes to maintain the option of nonideality in more rigorous alternative treatment.

The dielectric constant of the diluent equals 2.014; the diluent solubility parameter is set to 18.40 $\mathrm{J}^{1 / 2} \mathrm{~cm}^{-3 / 2}$. The dielectric constant is used in the model to calculate the formation constant of dissociated species (charged species) in the organic phase (see section 4.1.5). The dielectric constant of the diluent is low (consistent for an alkane-based diluent), but probably does not represent properly the polarity of the solvent after addition of the modifier at $0.75 \mathrm{M}$. The value of the dielectric constant as a parameter was increased to 12 , which represents the contribution from an alcohol to the alkane diluent [ 11 ] and used in the model. The solubility parameter of water is set to $51.13 \mathrm{~J}^{1 / 2} \mathrm{~cm}^{-3 / 2}$. 


\section{RESULTS AND DISCUSSION}

The approach taken to model the data is similar to that used previously [2]. A process-oriented model is described in section 4.1 and applied to series of data, including mixtures of sodium salts similar to known waste compositions. The approach taken to determine the best set of product species formed in the organic phase upon extraction and their corresponding formation constants for nitrate, hydroxide, chloride, nitrite, sulfate, carbonate, and fluoride media is presented. Influence of aluminate will also be discussed. In section 4.2, results toward a more rigorous model are described. Data sets including cesium, potassium, and sodium extraction from aqueous solutions containing only one anion per set are modeled with sets of species, each unique to each anion.

\subsection{DEVELOPMENT OF A PROCESS MODEL}

By way of organizing this section in direct fashion, the species defining the process model are presented first, following by results of testing the corresponding model against the experimental values obtained for cesium extraction from the different tank simulants. The investigation that led to the determination of the best set of species and their formation constants will then be presented in the subsequent sections. It was found that cesium and potassium extraction data from sodium media can be modeled very effectively with a simple model containing exclusively 1:1:1 species cation:anion:ligand, except for two species known to be present from other experimental observations. These exceptions include the sodium hydroxide ion pair, which is primarily extracted through its interaction with the modifier and therefore does not require the calixarene, and the dinuclear cesium nitrate complex $\left(\mathrm{CsNO}_{3}\right)_{2}$ Calix that can be formed at very high loading. The list of species required to model the data and their formations constants are presented in Table 5.

As mentioned above, the study started in FY02 involved additional anions, including sulfate, carbonate, fluoride, and aluminate. The results obtained with these anions will be discussed in sections 4.1.5 and 4.1.6. 
Table 5. List of species and formation constants used in this work

\begin{tabular}{cc}
\hline Species & $\begin{array}{c}\text { Formation constant } \\
\text { Log }_{10} \mathrm{~K}\end{array}$ \\
\hline $\mathrm{CsNO}_{3}$ Calix(o) & $3.591 \pm 0.029$ \\
$\left(\mathrm{CsNO}_{3}\right)_{2}$ Calix(o) & $7.681 \pm 0.084$ \\
$\mathrm{CsOHCalix}(\mathrm{o})$ & $3.357 \pm 0.016$ \\
$\mathrm{CsNO}{ }_{2}$ Calix(o) & $3.166 \pm 0.013$ \\
$\mathrm{CsClCalix}(\mathrm{o})$ & $2.709 \pm 0.013$ \\
$\mathrm{KNO}, \mathrm{Calix}(\mathrm{o})$ & $1.427 \pm 0.016$ \\
$\mathrm{KOHCalix}(\mathrm{o})$ & $1.385 \pm 0.017$ \\
$\mathrm{KNO}_{2} \mathrm{Calix}(\mathrm{o})$ & $1.135 \pm 0.015$ \\
$\mathrm{KClCalix}_{(0)}$ & $0.649 \pm 0.014$ \\
$\mathrm{NaOH}_{(0)}$ & $-0.805 \pm 0.036$ \\
$\mathrm{NaNO}_{3} \mathrm{Calix}(\mathrm{o})$ & $-0.803 \pm 0.041$ \\
$\mathrm{NaNO}_{2}$ Calix(o) & $-0.892 \pm 0.024$ \\
$\mathrm{NaClCalix}_{(0)}$ & $-1.250 \pm 0.025$ \\
\hline
\end{tabular}

(o) indicates the presence the species in the organic phase.

This basic set of species is very similar to the model determined in FY01 [2], except for the species $\mathrm{CsOH}(\mathrm{o})$ that was not determined to be necessary for this model. The formation constants are also very close to those obtained in FY01. They show an overall increase, which is due to the fact that the modifier concentration increased in the optimized solvent. This modifier concentration increase led to an increase in the distribution ratios, which cannot be directly accounted for by the model since modifier molecules are not included in the stoichiometry of species. The increase in the distribution ratios is modeled by an increase in the formation constant values.

\section{4..1.1 Tests using tank simulants}

Based on the model specified in Table 5, the fixed set of parameters may now be used to predict cesium distribution ratios from new aqueous phases where the initial conditions and concentrations are known. As a validation of the model, cesium extraction predictions were compared to experimental data obtained upon extracting cesium from five different waste-tank simulants. Actual waste batch tests conducted at the Savannah River Site provided the concentrations of major components (sodium, potassium, cesium, hydroxide, and nitrate) of the waste [12]. From these analytical data, simulants were prepared using either nitrite or chloride for cation-anion charge balance. These initial concentrations 
were entered into the appropriate input data file, and the program SXF'IT then predicted the corresponding cesium distribution ratio based on all the species and formation constants presented above. Table 6 presents the comparison between the measured distribution ratio and those that were predicted. Unlike the conditions used before, all $\mathrm{O} / \mathrm{A}$ volume ratios were 1/3. All experiments were carried out at 25 “ $\mathrm{C}$.

Table 6. Comparison of measured and predicted distribution ratios for tank simulants

\begin{tabular}{|c|c|c|c|}
\hline Tank & Composition & $\mathbf{D}_{\mathrm{Cs}}$ measured & $\mathbf{D}_{\mathrm{Cs}}$ predicted \\
\hline \multirow{6}{*}{ Tank 13} & {$\left[\mathrm{Na}^{+}\right]=5.6 \mathrm{M}$} & \multirow{6}{*}{5.73} & \multirow{6}{*}{6.97} \\
\hline & {$\left[\mathrm{K}^{+}\right]=0.067 \mathrm{M}$} & & \\
\hline & {$\left[\mathrm{Cs}^{+}\right]=0.512 \mathrm{mM}$} & & \\
\hline & {$[\mathrm{OH}-]=2.29 \mathrm{M}$} & & \\
\hline & {$\left[\mathrm{NO}_{3}^{-}\right]=0.767 \mathrm{M}$} & & \\
\hline & {$[\mathrm{NO}]=,2.6 \mathrm{M}$} & & \\
\hline \multirow{6}{*}{$\begin{array}{l}\text { Tank } 13 \\
\text { (with chloride, } \\
\text { substituted for nitrite) }\end{array}$} & {$\left[\mathrm{Na}^{+}\right]=5.6 \mathrm{M}$} & \multirow{6}{*}{4.60} & \multirow{6}{*}{5.64} \\
\hline & {$\left[\mathrm{K}^{+}\right]=0.067 \mathrm{M}$} & & \\
\hline & {$\left[\mathrm{Cs}^{+}\right]=0.512 \mathrm{mM}$} & & \\
\hline & {$[\mathrm{OH}-]=2.29 \mathrm{M}$} & & \\
\hline & {$[\mathrm{NO}]=,0.767 \mathrm{M}$} & & \\
\hline & {$[\mathrm{Cl}-]=2.6 \mathrm{M}$} & & \\
\hline \multirow{6}{*}{ Tank 26} & {$\left[\mathrm{Na}^{+}\right]=5.6 \mathrm{M}$} & \multirow{6}{*}{13.0} & \multirow{6}{*}{13.1} \\
\hline & {$\left[\mathrm{K}^{+}\right]=0.041 \mathrm{M}$} & & \\
\hline & {$\left[\mathrm{Cs}^{+}\right]=0.219 \mathrm{mM}$} & & \\
\hline & {$[\mathrm{OH}-]=4.71 \mathrm{M}$} & & \\
\hline & {$[\mathrm{NO}]=,0.956 \mathrm{M}$} & & \\
\hline & {$[\mathrm{NO}]=,0 \mathrm{M}$} & & \\
\hline \multirow{6}{*}{ Tank 33} & {$\left[\mathrm{Na}^{+}\right]=3.3 \mathrm{M}$} & \multirow{6}{*}{14.0} & \multirow{6}{*}{13.2} \\
\hline & {$\left[\mathrm{K}^{+}\right]=5 \mathrm{mM}$} & & \\
\hline & {$\left[\mathrm{Cs}^{+}\right]=8.03 \mu \mathrm{M}$} & & \\
\hline & {$[\mathrm{OH}-]=1.47 \mathrm{M}$} & & \\
\hline & {$[\mathrm{NO},-]=1.44 \mathrm{M}$} & & \\
\hline & {$[\mathrm{NO}]=,0.4 \mathrm{M}$} & & \\
\hline \multirow{6}{*}{ Tank 35} & {$\left[\mathrm{Na}^{+}\right]=5.6 \mathrm{M}$} & \multirow{6}{*}{17.9} & \multirow{6}{*}{17.0} \\
\hline & {$\left[\mathrm{K}^{+}\right]=0.01 \mathrm{M}$} & & \\
\hline & {$\left[\mathrm{Cs}^{+}\right]=0.188 \mathrm{mM}$} & & \\
\hline & {$[\mathrm{OH}-]=2.93 \mathrm{M}$} & & \\
\hline & {$[\mathrm{NO}]=,1.4 \mathrm{M}$} & & \\
\hline & {$[\mathrm{NO}]=,1.3 \mathrm{M}$} & & \\
\hline
\end{tabular}




\begin{tabular}{|c|c|c|c|}
\hline Tank & Composition & $\mathrm{D}_{\mathrm{Cs}}$ measured & $\mathbf{D}_{\mathbf{C s}}$ predicted \\
\hline \multirow{6}{*}{ Tank 46} & {$\left[\mathrm{Na}^{+}\right]=5.6 \mathrm{M}$} & \multirow{6}{*}{12.3} & \multirow{6}{*}{14.1} \\
\hline & {$\left[\mathrm{K}^{+}\right\rceil=0.032 \mathrm{M}$} & & \\
\hline & {$\left[\mathrm{Cs}^{+}\right]=0.378 \mathrm{mM}$} & & \\
\hline & {$[\mathrm{OH}-]=3.98 \mathrm{M}$} & & \\
\hline & {$[\mathrm{NO} ;]=0.606 \mathrm{M}$} & & \\
\hline & {$[\mathrm{NO}]=,1.0 \mathrm{M}$} & & \\
\hline \multirow{6}{*}{$\begin{array}{l}\text { Tank } 46 \\
\text { (with chloride } \\
\text { substituted for nitrite) }\end{array}$} & {$\left[\mathrm{Na}^{+}\right]=5.6 \mathrm{M}$} & \multirow{6}{*}{11.0} & \multirow{6}{*}{12.9} \\
\hline & {$\left[\mathrm{K}^{+}\right]=0.032 \mathrm{M}$} & & \\
\hline & {$\left[\mathrm{Cs}^{+}\right]=0.378 \mathrm{mM}$} & & \\
\hline & {$\left[\mathrm{OH}^{-}\right]=3.98 \mathrm{M}$} & & \\
\hline & {$\left[\mathrm{NO}_{2}{ }^{-}\right]=0.606 \mathrm{M}$} & & \\
\hline & {$[\mathrm{Cl}-]=1.0 \mathrm{M}$} & & \\
\hline
\end{tabular}

The prediction is relatively good for any composition of the simulant. Overall, predictions agree with the experimental results to within an average of $\pm 10 \%$. This test is probably the best validation for the model described previously. In the next sections, the step-by-step method to determine the different organic product species and their formation constants (Table 5) is explained.

\subsubsection{Single sodium salt media}

In order to develop the model targeting primarily process conditions, only the extraction of potassium and cesium from solutions of sodium salts was studied and modeled. The easiest method to determine the kind of species that are formed and to run calculations that will predict the best formation constants is to study single-anion systems, one for each of the four major anions. Extraction of cesium from those single salts was modeled first. The values of the formation constants obtained after fitting those data sets were pooled together, and this model was then tested without refinement using new data corresponding to binary, ternary, and quaternary systems. The fitting results for each set (per anion) are presented in Figures 1 through 4. Owing to formatting limitations in the plotting software, no subscripts nor superscripts are shown in any of the graph legends. For a cation $\mathrm{M}$ ( $\mathrm{M}$ being Na, K, or $\mathrm{Cs}$ ), DM= $\mathrm{D}_{\mathbf{M}}$ and $[\mathrm{M}+]$ init $=\left[\mathrm{M}^{+}\right]_{\text {init }}$, where the subscript "init" indicates initial concentration. 


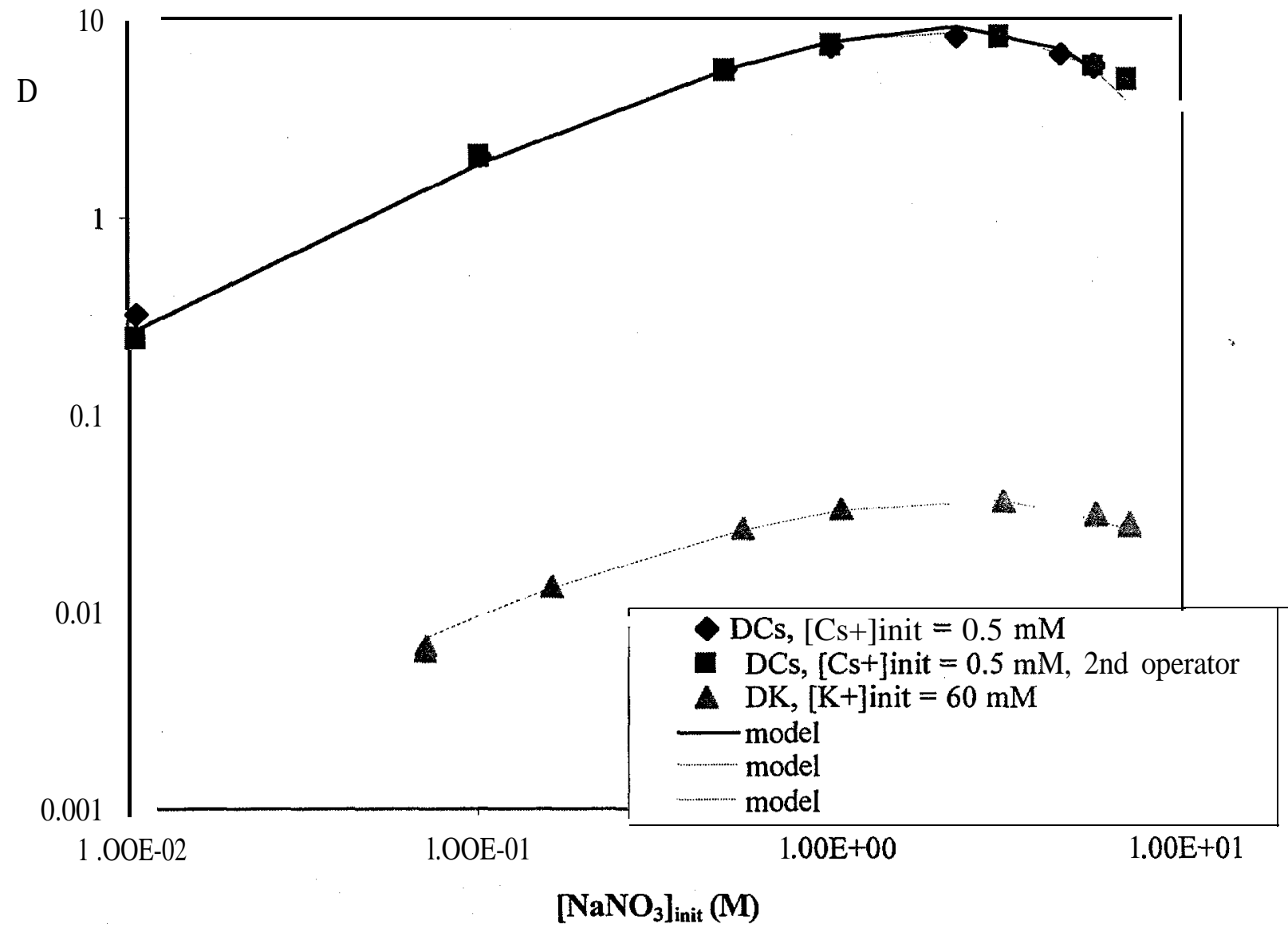

Fig. 1. M odeling of cesium and potassium distribution ratios for the nitrate media. The " 2 nd operator" notation in the legend indicates a repeat of the extraction test by an operator other than the operator who collected the data represented by the diamond symbols. 


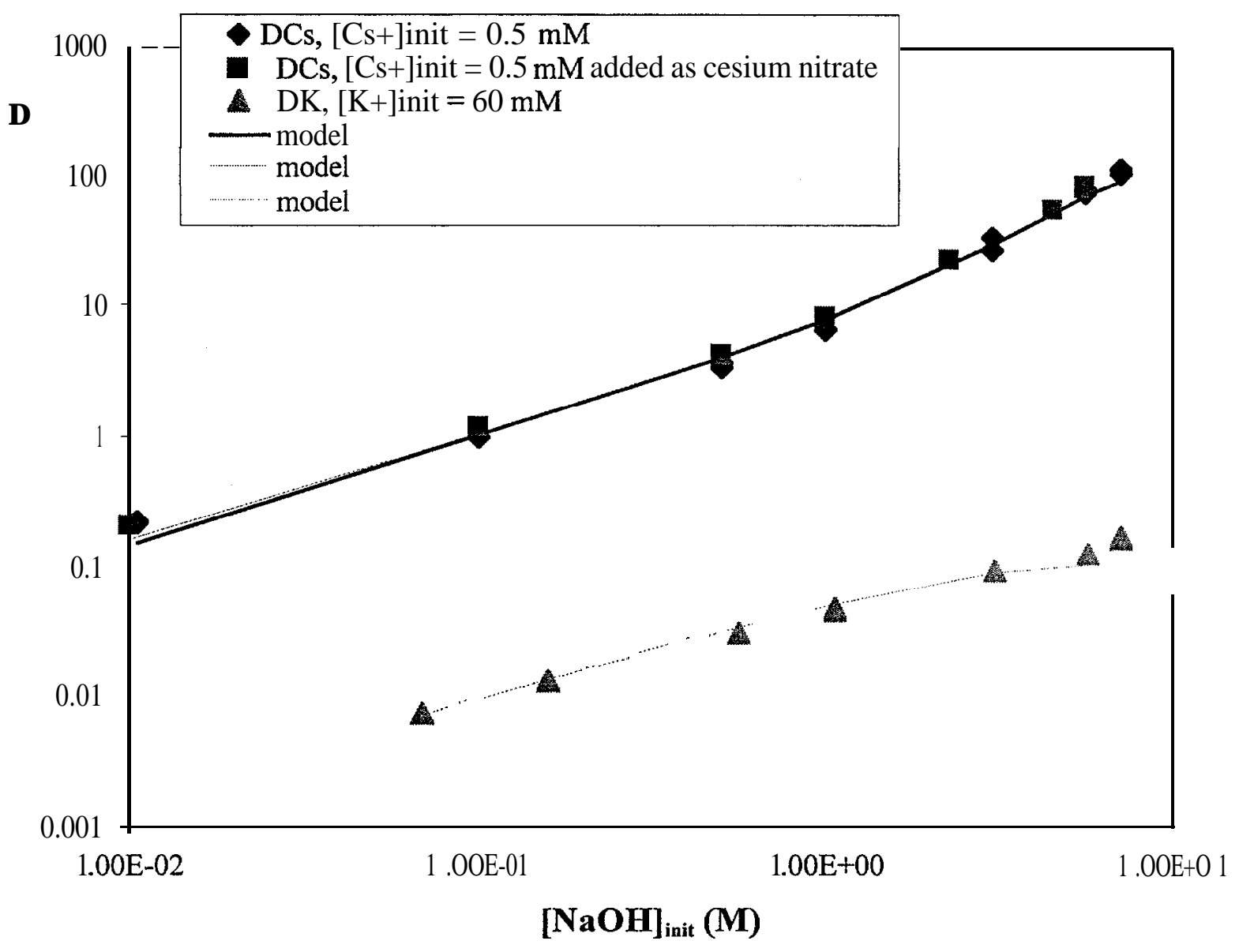

Fig. 2. M odeling of cesium and potassium distribution ratios for the hydroxide media

Unlike the behavior seen with the other salts, cesium and potassium distribution ratios do not level off at high sodium hydroxide concentration. With the other salts, even if the distribution ratios of sodium by the calixarene are minimal compared to those for cesium, at high sodium concentration, the total amount of sodium extracted is no longer negligible and the calixarene exhibits loading effects. When using sodium hydroxide, it is believed that a small fraction of the modifier is deprotonated and acts as a cation exchanger, leading to an increase in the distribution ratios. A more thorough explanation can be found in section 4.2.2. 


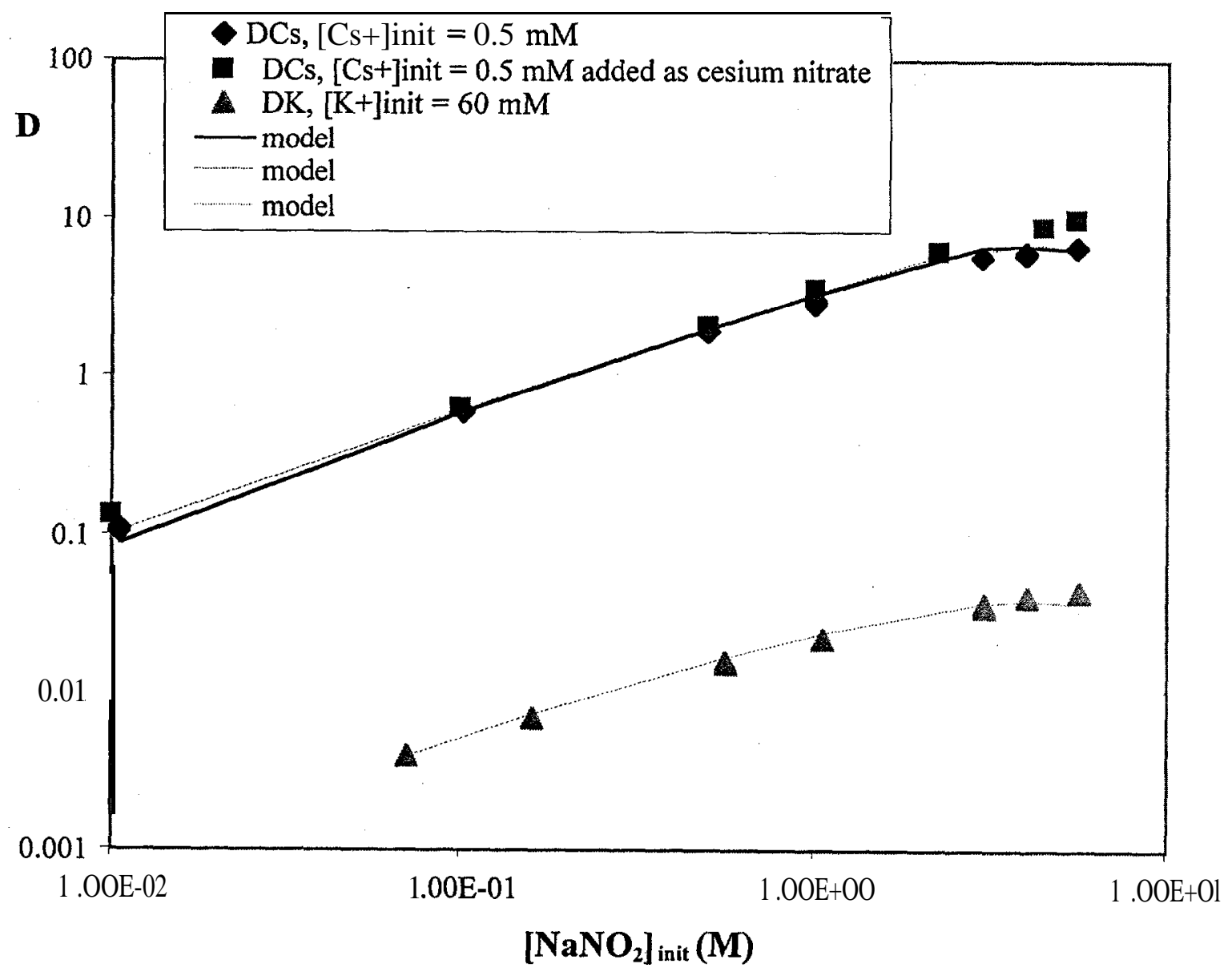

Fig. 3. M odeling of cesium and potassium distribution ratios for the nitrite media 


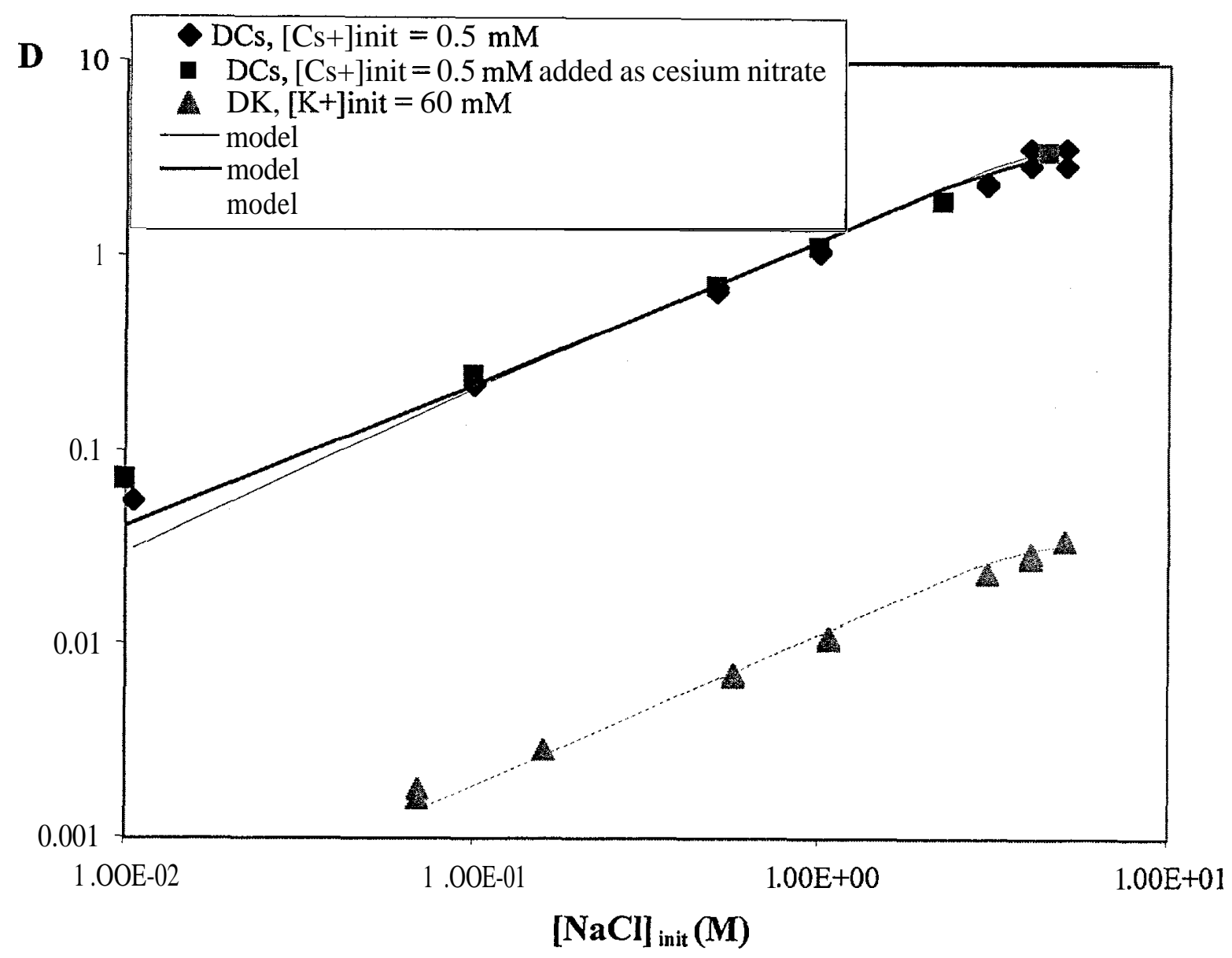

Fig. 4. M odeling of cesium and potassium distribution ratios for the chloride media

This model determined with single salts above was then tested with more complex systems presented below. The predictions are compared to the results obtained in media of increasing complexity, where two, then three, then four different sodium salts are mixed.

\subsubsection{Systems containing a mixture of two sodium salts}

Systems that were tested involve a fixed concentration of cesium in a mixture of two sodium salts. Extraction of cesium from the six combinations of sodium nitrate, hydroxide, nitrite, and chloride was experimentally investigated and then predicted by the model defined above. The results shown in Figures 5-7 were obtained without changing any of the formation-constant values established in the previous section. 


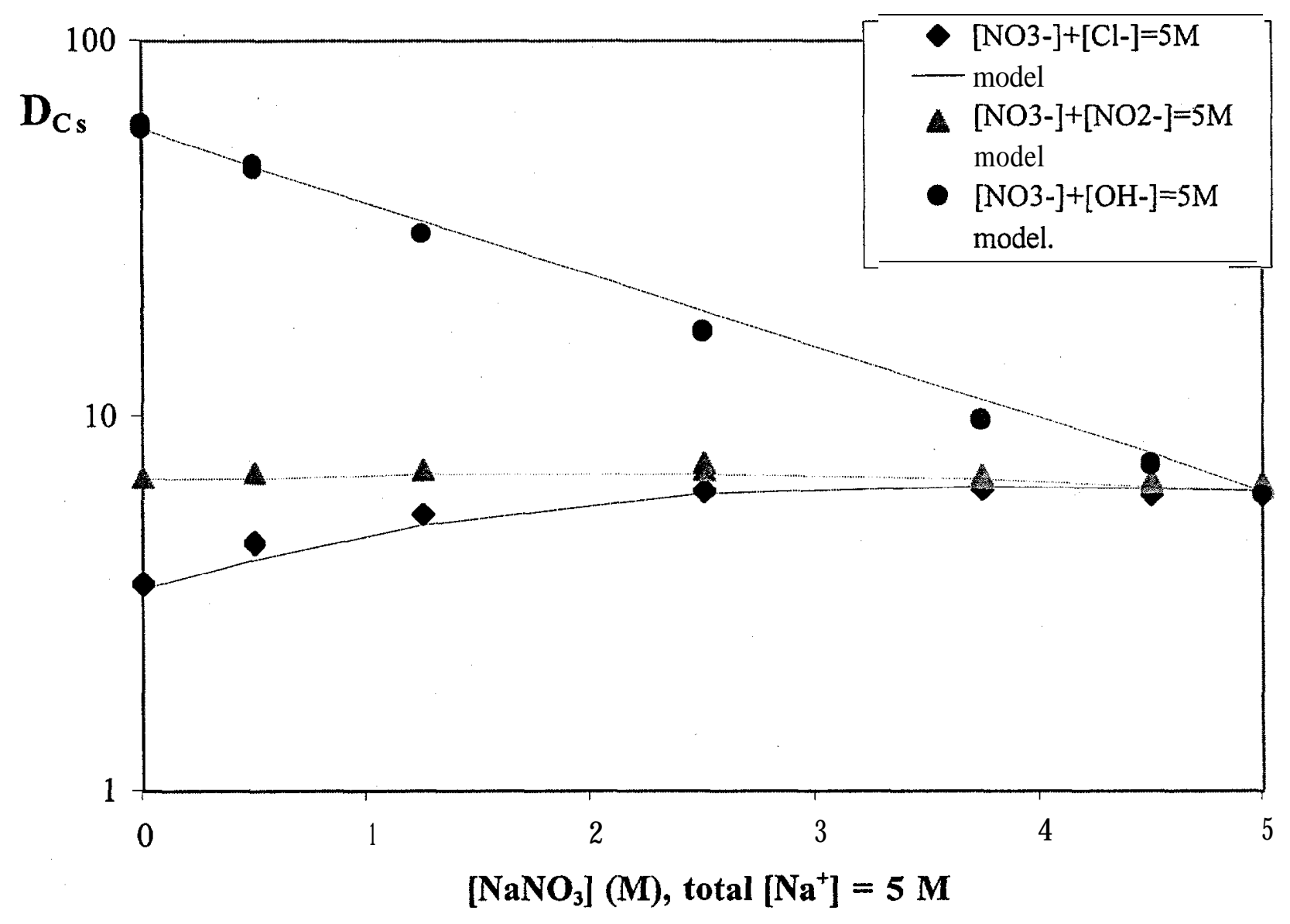

Fig. 5. M odeling of cesium distribution ratios for nitrate-based systems 


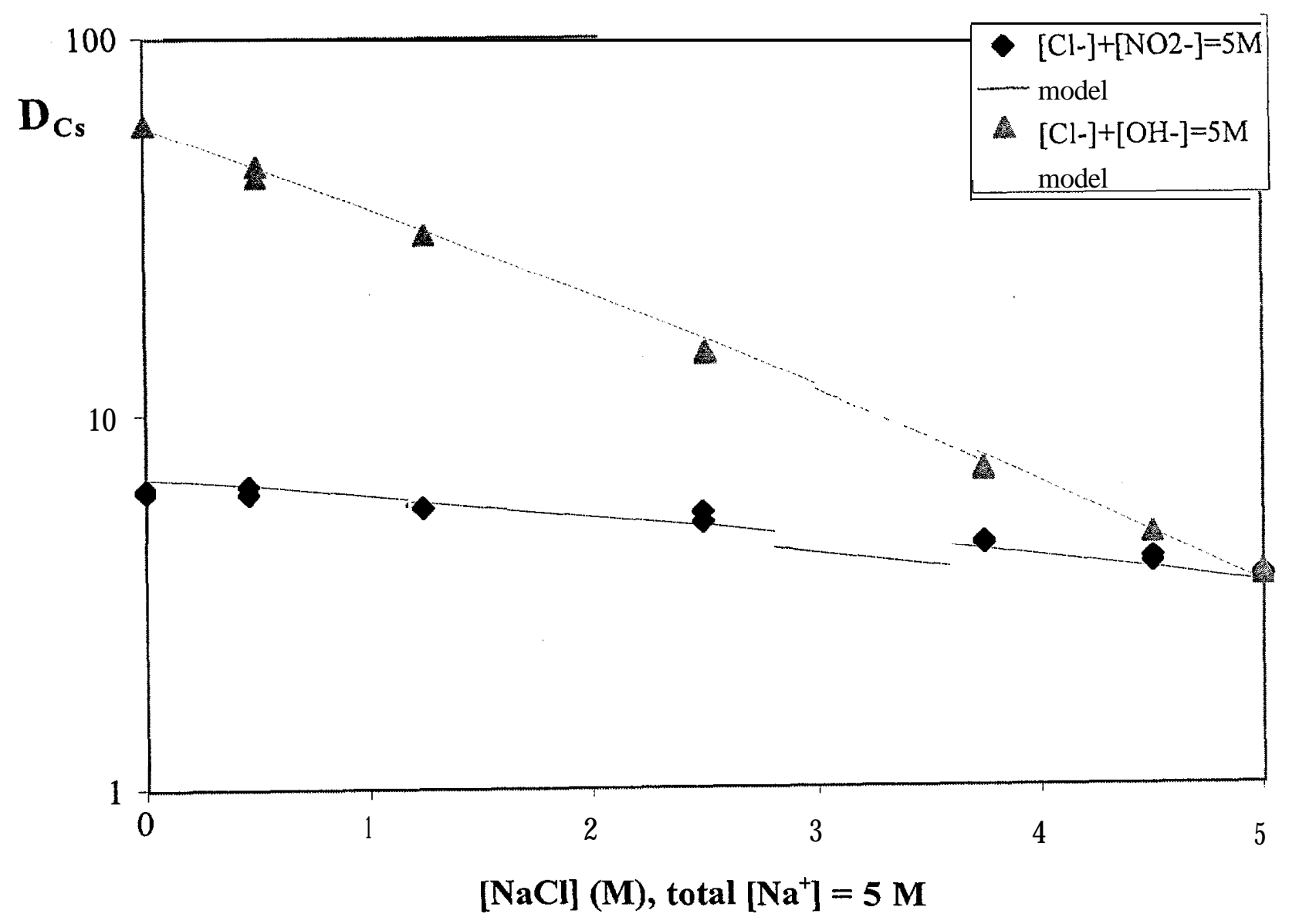

Fig. 6. M odeling of cesium distribution ratios for chloride-based systems 


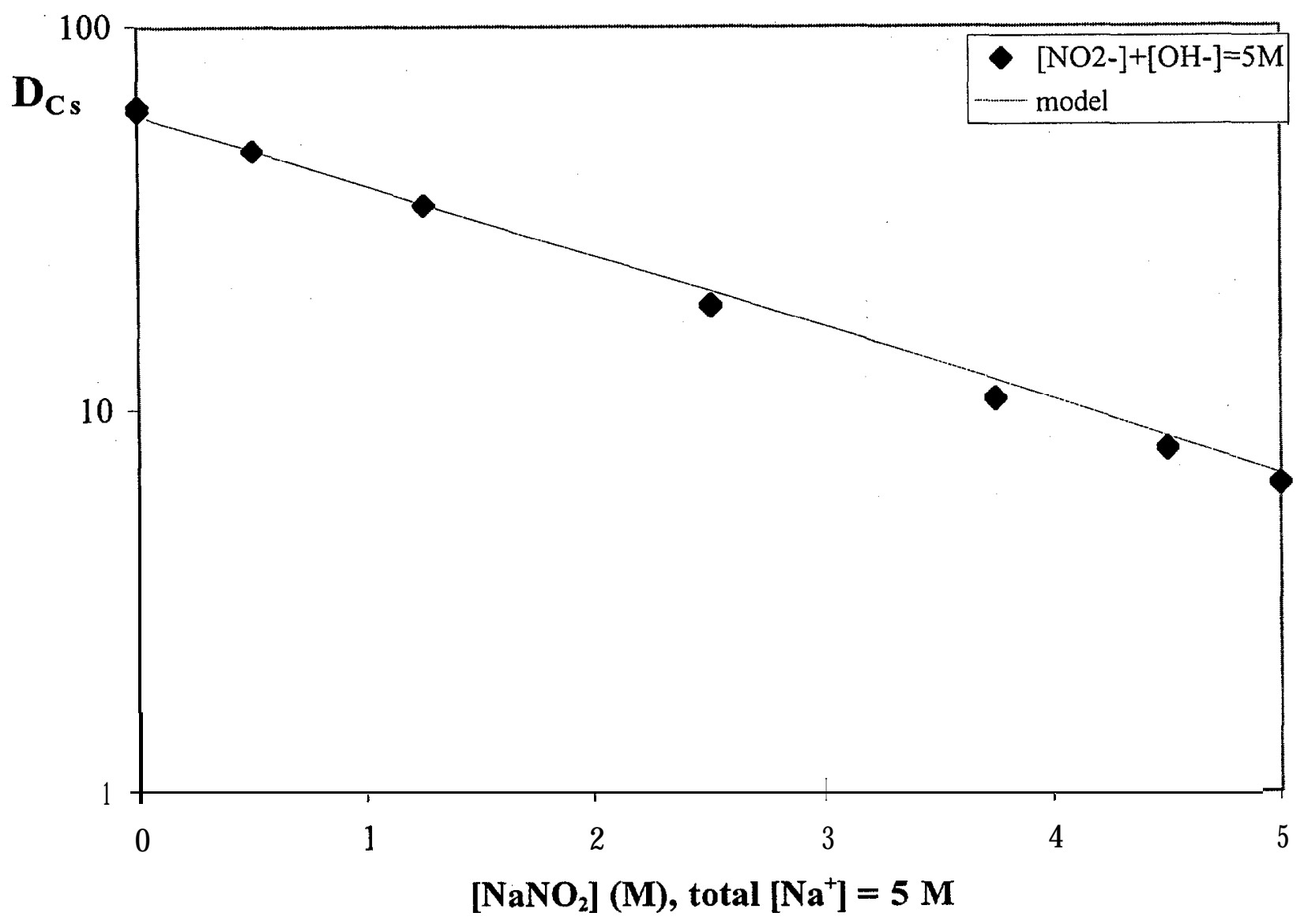

Fig. 7. M odeling of cesium distribution ratios for nitrite-based system

The cesium distribution ratios calculated by the model based on the initial compositions are very close to those observed experimentally. This test, involving two-sodium salts systems, gives a good indication that more complex systems, such as those described in the following section, should also be correctly predicted.

\subsubsection{Systems containing a mixture of three or four sodium salts}

Systems with multiple sodium salts were prepared using sodium chloride and sodium nitrite as background salts while the relative proportions of sodium hydroxide and sodium nitrate were varied. These compositions represent an extra step toward the compositions likely to be found in the actual waste, and are therefore also a logical trial and test for the model developed with single salts. Figure 8 presents 
the results obtained when varying the concentrations of hydroxide and nitrate while keeping constant at 1 or $2 \mathrm{M}$ either sodium chloride or sodium nitrite. The predictions are very close to the observed values.

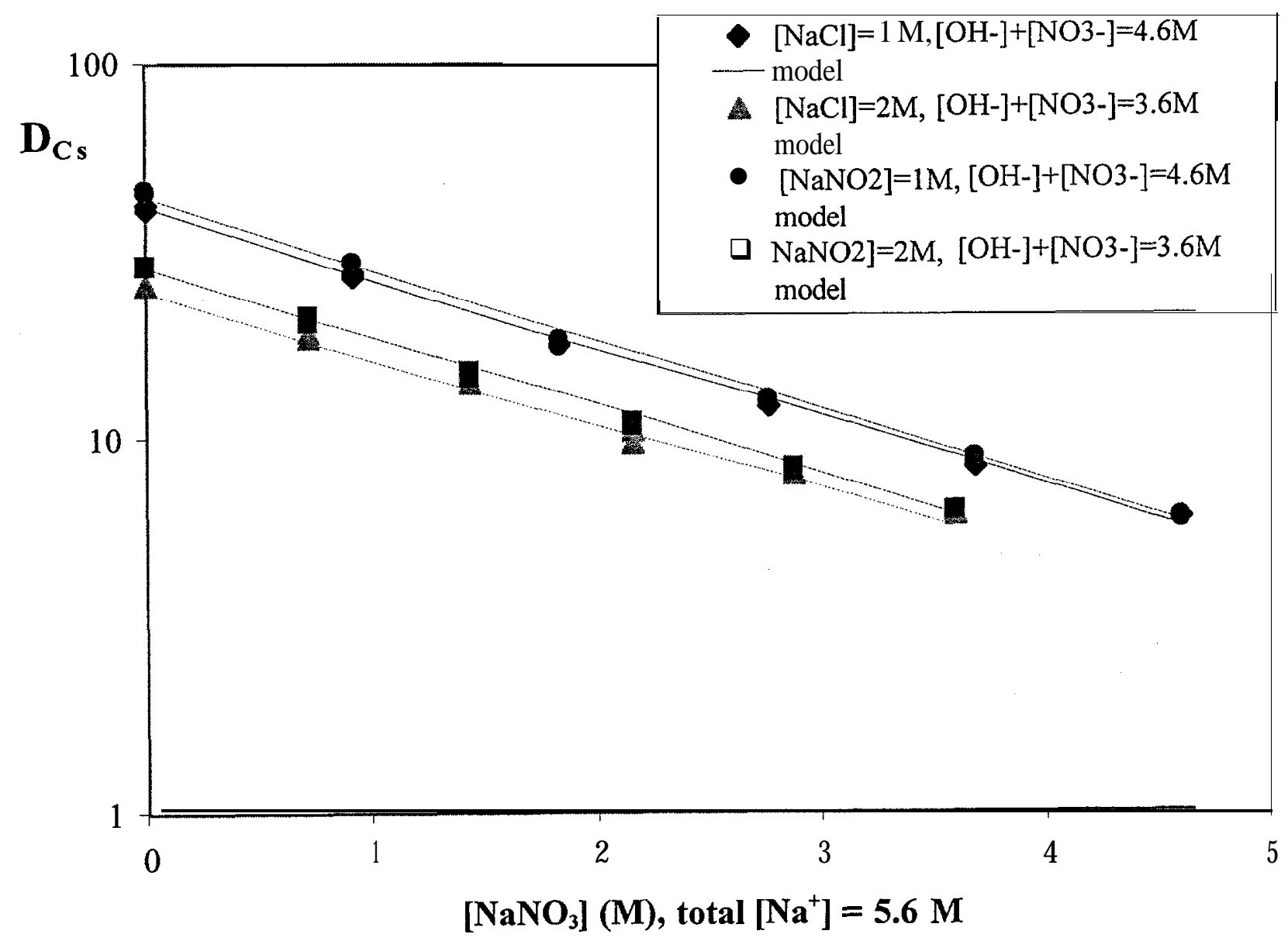

Fig. 8. M odeling of cesium distribution ratios for three sodium salts data sets

A final experiment was conducted where the two concentrations of sodium nitrite and sodium chloride were each maintained at $1 \mathrm{M}$, while the relative proportion of nitrate and hydroxide varied. Again, the model was applied to the initial conditions without refinement of the parameters. Comparison between the observed and calculated values is presented in Figure 9. 


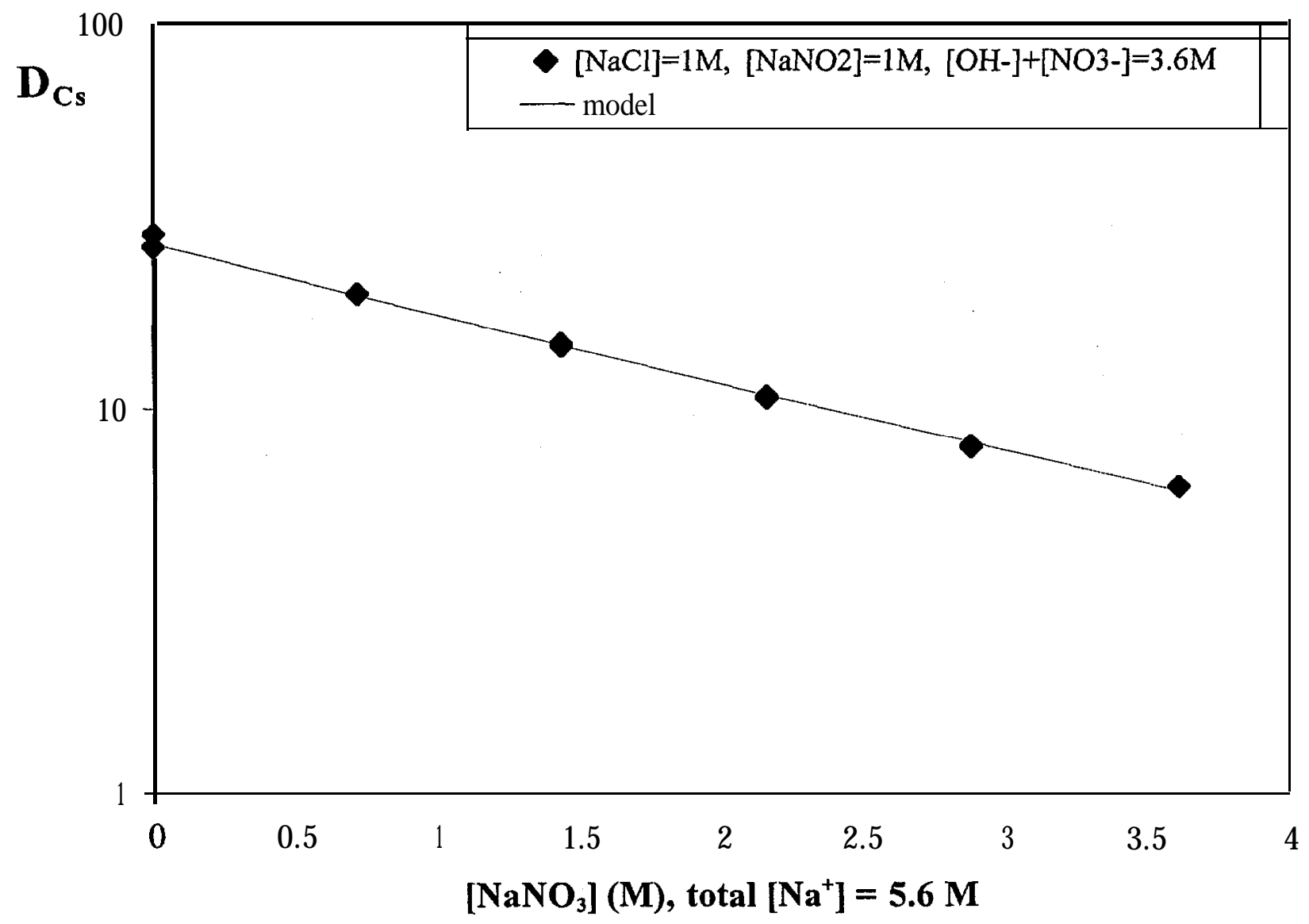

Fig, 9. M odeling of cesium distribution ratios for four sodium salts data set

It has been demonstrated that the list of species and the corresponding formation constants fixed in Table 5 gives a model that permits the calculation of cesium extraction not only from single salts but also from a variety of mixtures of salts that are known to be in the largest concentrations in the actual wastes. The last verification and validation consisted in using the extraction results obtained with the optimized solvent and different tank simulants, which we showed was successful in section 4.1.1 of this chapter.

The list of species presented at the beginning of this chapter (Table 5) did not include any species containing other anions, such as sulfate, fluoride, carbonate, or aluminate, known to be present in the waste. Systems including these anions were studied, and the results are presented in the following sections. 


\subsubsection{Carbonate, sulfate, and fluoride media}

Carbonate, sulfate, and fluoride are three anions that were not studied in FY01. Their inclusion in the present study comes from the fact that carbonate and sulfate, even if they are in relatively small concentration in the waste, contributes significantly to the total ionic strength of the system (as the contribution is proportional to the square of the ion charge). Fluoride is present in the waste in concentrations that can be greater than chloride concentrations. The impact of these ions on the extraction system needed to be studied. Cesium extraction from sodium fluoride, sodium sulfate, and sodium carbonate at different concentrations was measured and modeled. The results are presented in Table 9 and Figure 10.

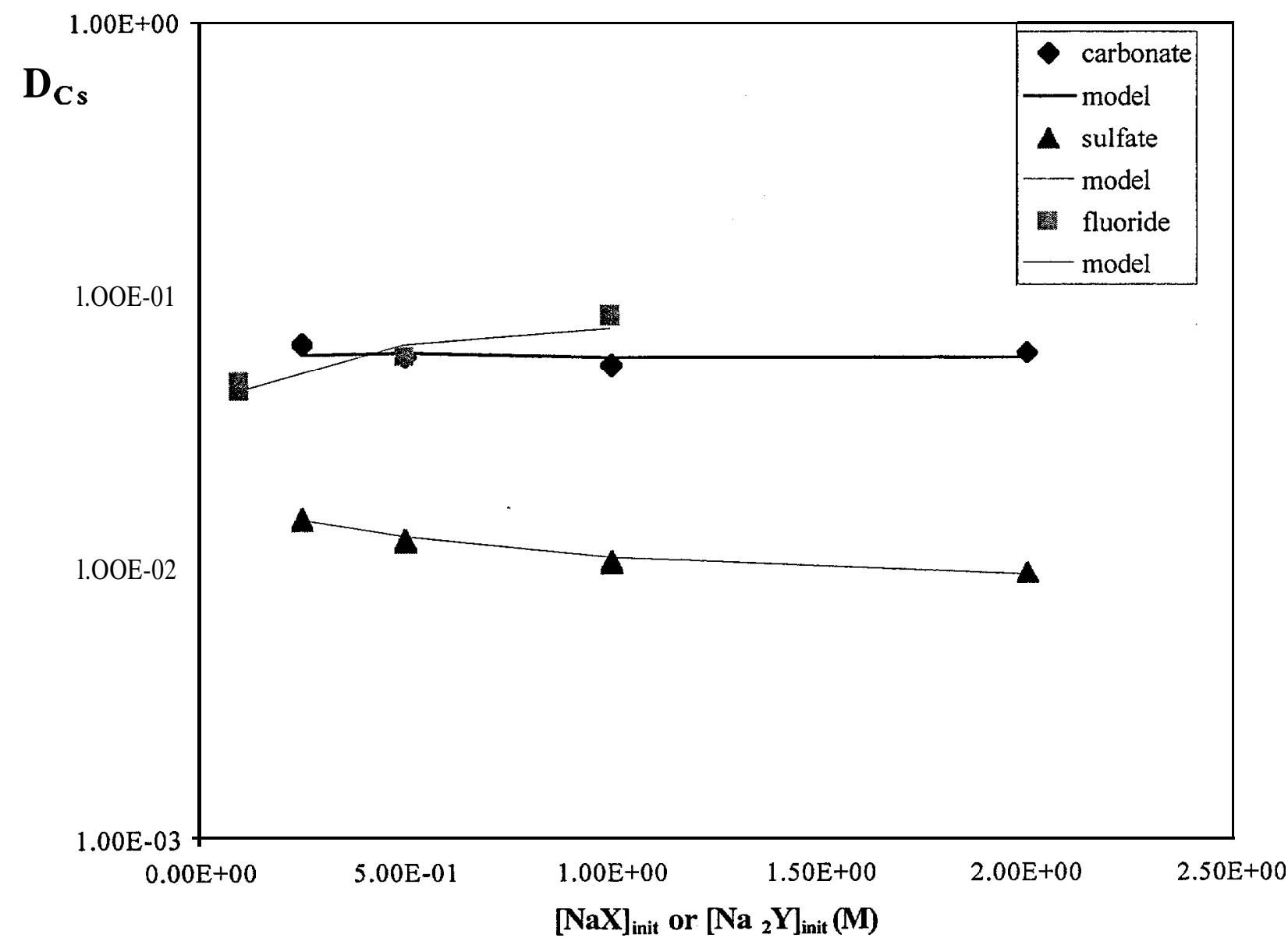

Fig. 10. M odeling of cesium distribution ratios for fluoride, sulfate, and carbonate media 
Table 7. Formation constal for the model including fluoride, sulfate, and carbonate media

\begin{tabular}{|c|c|c|c|c|c|}
\hline Species & $\begin{array}{c}\text { Formation } \\
\text { constant } \\
\text { Log }_{1,} K\end{array}$ & Species & $\begin{array}{c}\text { Formation } \\
\text { constant } \\
\text { Log, } K\end{array}$ & Species & $\begin{array}{c}\text { Formation } \\
\text { constant } \\
\text { Log }_{1,} \mathrm{~K}\end{array}$ \\
\hline NaCalix'(o) & $-5.45 \pm 1.01$ & $\operatorname{NaCalix}^{+}(0)$ & $-2.68 \pm 0.17$ & $\operatorname{NaCalix}^{+}(\mathrm{o})$ & $-6.1 \pm 8.6$ \\
\hline $\operatorname{CsCalix}^{+}(0)$ & $-2.29 \pm 0.38$ & $\operatorname{CsCalix}^{+}(0)$ & $-1.01 \pm 0.04$ & $\operatorname{CsCalix}^{+}(\mathrm{o})$ & $-0.603 \pm 0.026$ \\
\hline$F^{-}(0)$ & 0 & $\mathrm{SO}_{4}{ }^{2-}(\mathrm{o})$ & 0 & $\mathrm{CO}_{3}{ }^{2-}(\mathrm{o})$ & 0 \\
\hline
\end{tabular}

All cesium distribution ratios obtained from these media are relatively low. Accordingly, organic-phase species that have to be included in the models are dissociated. An explanation for this behavior was given earlier [15]. Should a system include any of these anions and any of those presented above, the contribution of fluoride, carbonate, or sulfate toward cesium extraction would be extremely small. It is therefore recommended not to include any of these organic-phase species in the process model. However, as mentioned above, the impact of these anions on the ionic strength of the aqueous media may not be negligible, and the extension of the model regarding these anions would be effectively achieved by specifying their concentrations as part of the initial aqueous composition used as input data and by including the corresponding Pitzer parameters in the input parameter set to obtain a better definition of the interactions in the aqueous phase.

\subsubsection{Aluminate media}

A similar situation was encountered in assessing the influence of the presence of aluminate in the waste simulant. Aluminate is present in relatively large concentrations $(0.28 \mathrm{M}$ in the average simulant recipe) and may be more extractable than divalent anions. However, in order to obtain aluminate in solution, a sufficiently large concentration of free hydroxide needs to be maintained. Instead of a fairly simple system as presented above with sulfate, carbonate, and fluoride, this system thus entails a competition between hydroxide and aluminate. Two attempts to determine the amount of aluminate extracted along with cesium were performed, one by stripping the organic phase after extraction, one by ashing the solvent after extraction. The stripping phase or the ashes dissolved in nitric acid were then analyzed by ICP. In both cases, the amount of aluminum detected was barely above the detection limit, which corresponds to distribution ratios between $10^{-6}$ and $10^{-5}$. From this experiment, it can be concluded that aluminate is essentially inextractable in this system, nor does it have a major impact on cesium extraction. Thus, no organic-phase aluminate species will then be added to the model. The only expected 
influence is due to its effect on aqueous activity coefficients. The Pitzer parameters for the interactions between sodium and aluminate are $\beta_{0}=0.051, \beta_{1}=0.25$, and $C^{\Phi}=-0.0009$ [13]. Parameters involved in the three-ion interactions are also tabulated [14] for the interaction $\mathrm{Na}-\mathrm{OH}-\mathrm{Al}(\mathrm{OH})_{4}$ where $\theta=0.014$ and $\psi=-0.0048$.

\subsection{TOWARD A MORE RIGOROUS THERMODYNAMIC MODEL}

The model described in the previous section comprises species and formation constants that give a very good prediction for the extraction of cesium and potassium from mixtures of sodium salts representative of Savannah River salt waste. The model is fairly simple and fulfills the requirements of predicting cesium and potassium extraction from actual waste. Potassium is important because it can load the extractant and thereby depress cesium extraction. It is also associated with third-phase formation [16]. In principle, a truly thermodynamic model should also be able to predict the extraction of cesium from cesium salts, potassium from potassium salts, or sodium from sodium salts. This question was not addressed in the development of the process model. Because a more rigorous model was expected to be more robust to gross changes in waste composition, some effort was devoted toward a more comprehensive treatment. In addition, it was judged desirable to include sodium distribution in the model if possible, as sodium extraction by the solvent is significant [16]. For these reasons, we investigated and modeled the behavior of systems each containing only one anion and mixtures of the three cations sodium, potassium, and sodium. The species and corresponding formation constants are presented for each medium.

\subsubsection{N itrate media}

The modeling of this series of species included taking into account the extraction of sodium from sodium nitrate by a solvent with and without calixarene, the extraction of potassium from potassium or sodium nitrate, and similarly, the extraction of cesium from cesium or sodium nitrate. The approach involved modeling extraction of sodium from sodium nitrate, potassium from potassium nitrate, and cesium from cesium nitrate with a minimum number of species. Cesium and potassium extraction data from sodium nitrate were then modeled using the species determined in the first step. All extraction data (sodium, potassium, and cesium) from the different nitrate media were all pooled together. The formation 
constants of the organic product species were refined using the entire data set. This approach was the same for the other anion systems described in section 4.2.2 through 4.2.4.

Table 8 summarizes the formation constants and species needed for the nitrate model. In this and all following tables, the indication (o) shows that the species is formed in the organic phase.

Table 8. Species and formation constants for the model derived for nitrate data

\begin{tabular}{lc}
\hline Species & $\begin{array}{c}\text { Formation constant } \\
\text { Log, } \mathrm{K}\end{array}$ \\
\hline $\mathrm{NaNO}_{3}(\mathrm{o})$ & $-4.746 \pm 0.018$ \\
$\mathrm{NaNO}_{3}$ Calix(o) & $-1.470 \pm 0.067$ \\
$\mathrm{NaNO}_{3} \mathrm{Calix}_{2}(\mathrm{o})$ & $0.40 \pm 0.20$ \\
$\mathrm{KNO}_{2} \mathrm{Calix}(\mathrm{o})$ & $1.411 \pm 0.016$ \\
$\mathrm{CsNO}_{3}(\mathrm{o})$ & $-2.8 \pm 1.4$ \\
$\mathrm{CsNO}_{3} \mathrm{Calix}(\mathrm{o})$ & $3.672 \pm 0.008$ \\
$\left(\mathrm{CsNO}_{3}\right)_{2} \mathrm{Calix}(\mathrm{o})$ & $5.00 \pm 0.17$ \\
\hline
\end{tabular}

Observed and calculated data are presented in Figure 11 for potassium and sodium extraction and in Figure 12 for cesium extraction. Some of the data were obtained using a solvent that is calixarene-free. The model shows that the presence of calixarene increases sodium extraction from sodium nitrate. 


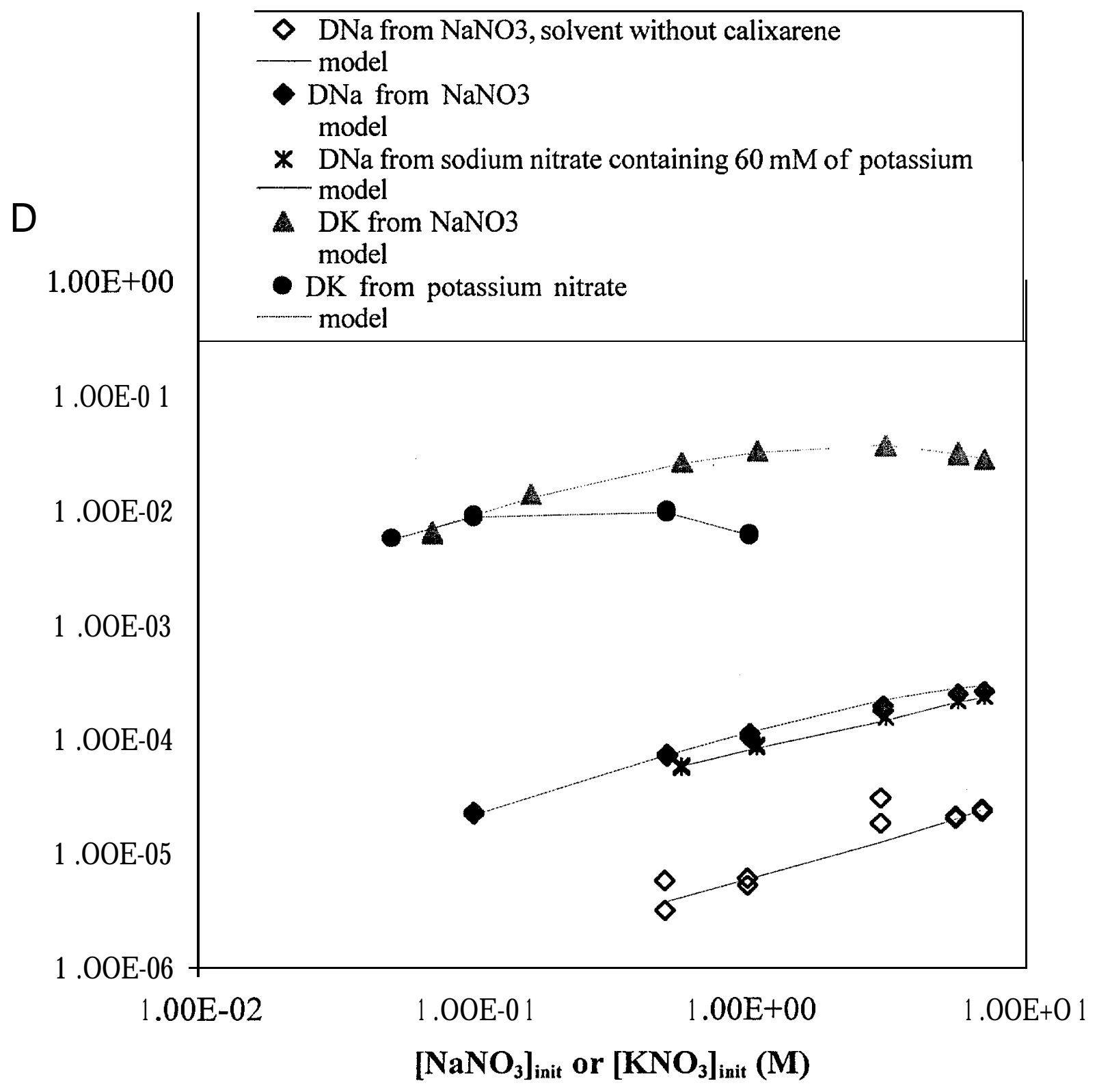

Fig. 11. M odeling of potassium or sodium distribution ratios for nitrate media

At high concentrations of sodium nitrate where loading and activity effects are having the most effect, potassium distribution ratios reach a maximum and then decrease, a phenomenon also seen for cesium distribution ratios in Figure 12. 


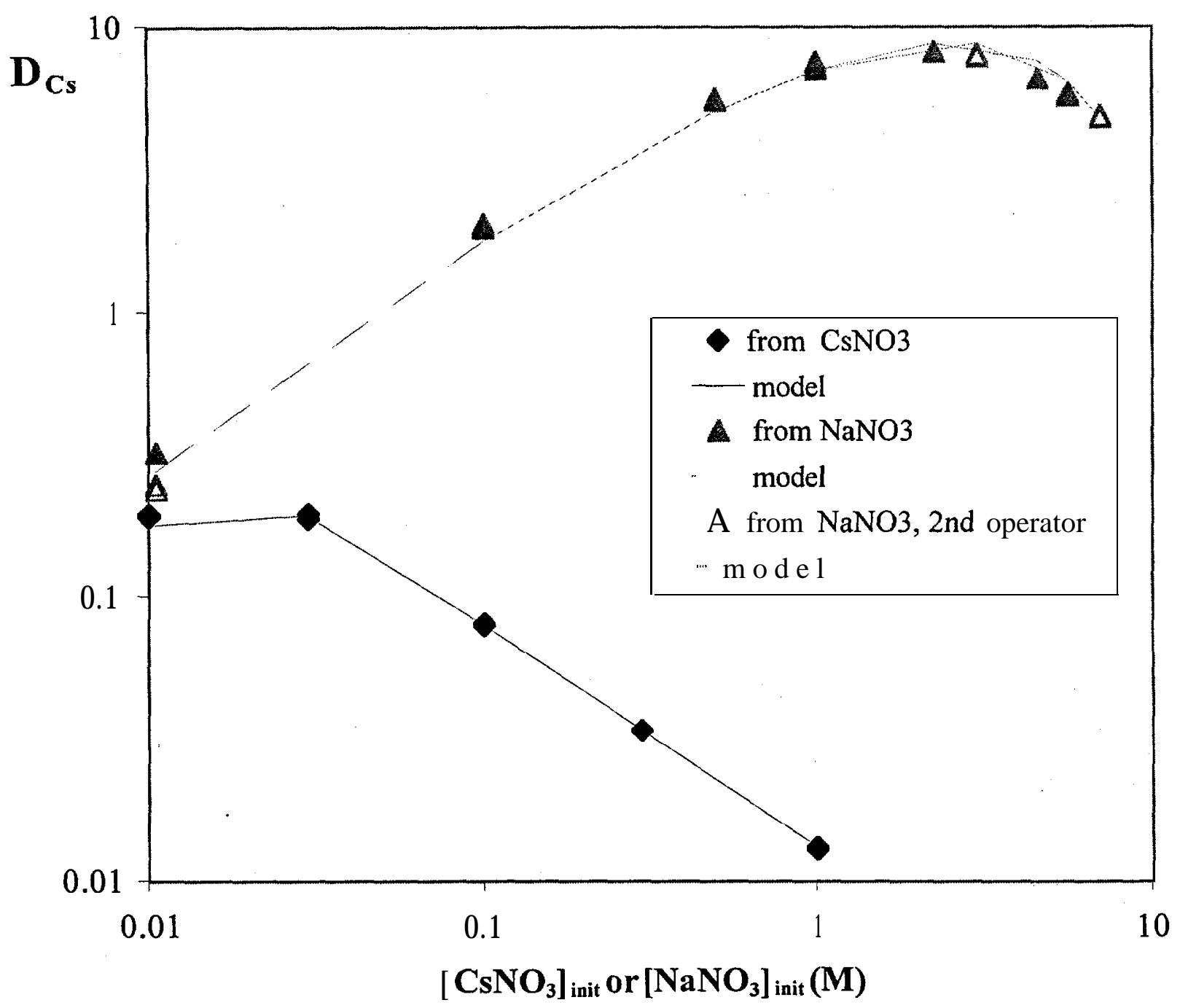

Fig. 12. M odeling of cesium distribution ratios for nitrate media

The overall model gives a very good prediction of all data available even if it seems to over-predict the cesium extraction at high ionic strength. Limitations of the activity-coefficient corrections based on tabulated Pitzer parameters are likely significant at high ionic strength. For greatest accuracy, it would be necessary to obtain Pitzer parameters calculated for salt concentration ranges including our system conditions. No cesium extraction data obtained using a solvent without BOBCalixC6 were presented, as the cesium distribution ratios were extremely low $\left(10^{-4}-10^{-6}\right)$. 


\subsubsection{Hydroxide media}

The second set of data involves the fitting of cation extraction from sodium hydroxide. Results shown in Figure 13 demonstrate that the presence of calixarene is not required to extract sodium from sodium hydroxide, as the amount of sodium present in the organic phase was the same whether or not the calixarene was present in the solvent. It is likely that the modifier starts being deprotonated and begins to behave as a cation exchanger, as discussed previously [16]. Only this assumption can explain the large (for example with sodium nitrate) sodium distribution ratios observed in the hydroxide system.

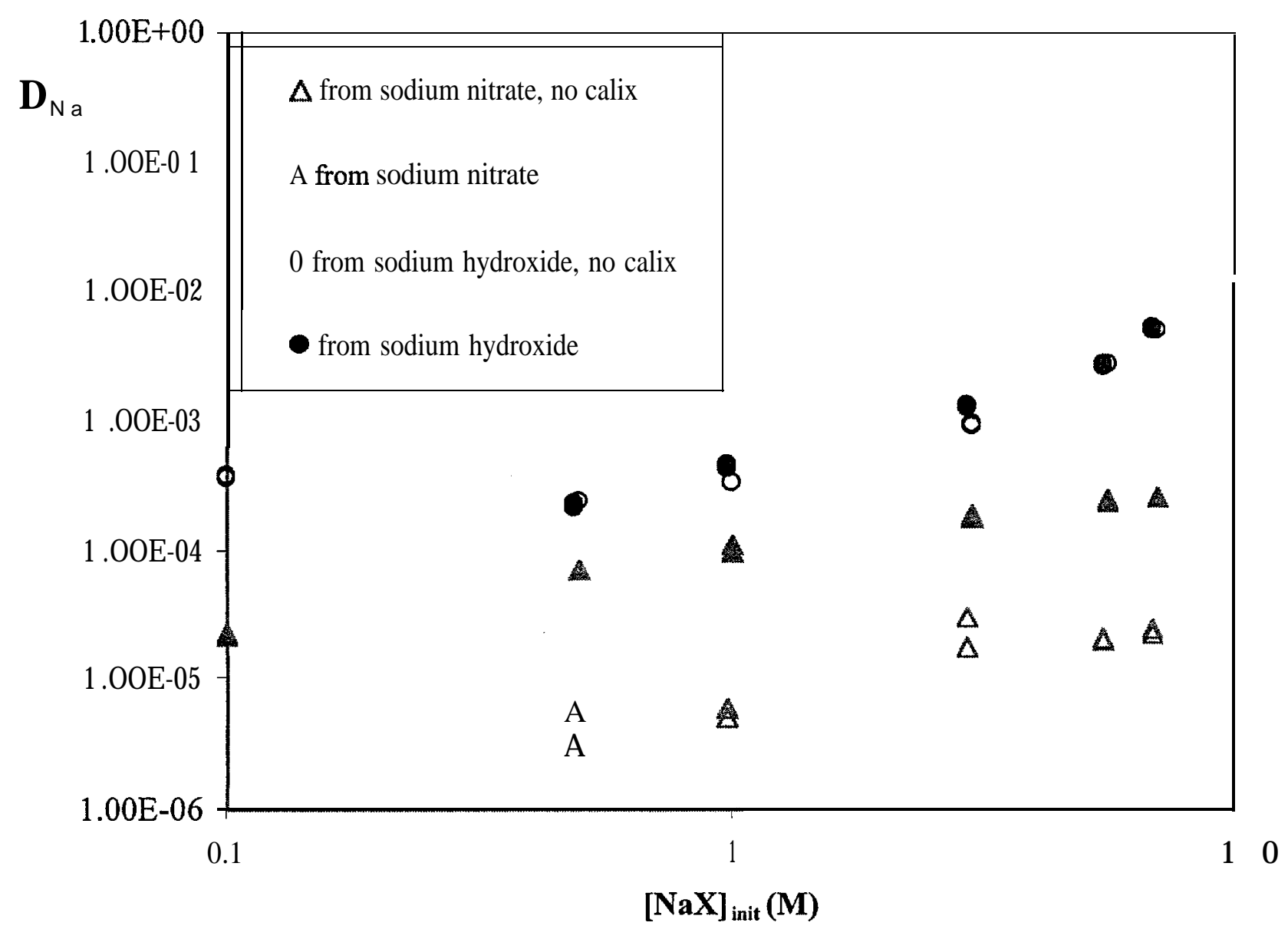

Fig. 13. Extraction of sodium (with and without calixarene) and comparison between the nitrate and hydroxide media

From this experiment, it is obvious that the only species to consider in the future is the ion pair $\mathrm{NaOH}(\mathrm{o})$, and that any species containing a calixarene would probably be rejected by the model. The species listed in Table 9 define a model to achieve a fit of data obtained in hydroxide systems. Figure 14 summarizes the fit as a function of hydroxide concentration. 
Table 9. Species and formation constants for the model derived for hydroxide data

\begin{tabular}{lc}
\hline Species & $\begin{array}{c}\text { Formation constant } \\
\log _{10} \mathrm{~K}\end{array}$ \\
\hline $\mathrm{NaOH}(\mathrm{o})$ & $-0.715 \pm 0.085$ \\
$\mathrm{KOH}(\mathrm{o})$ & $-2.68 \pm 0.18$ \\
$\mathrm{KOHCalix}(\mathrm{o})$ & $1.365 \pm 0.019$ \\
$\mathrm{CsOH}(\mathrm{o})$ & $-2.044 \pm 0.038$ \\
$\mathrm{CsOHCalix}(\mathrm{o})$ & $3.416 \pm 0.024$ \\
\hline
\end{tabular}

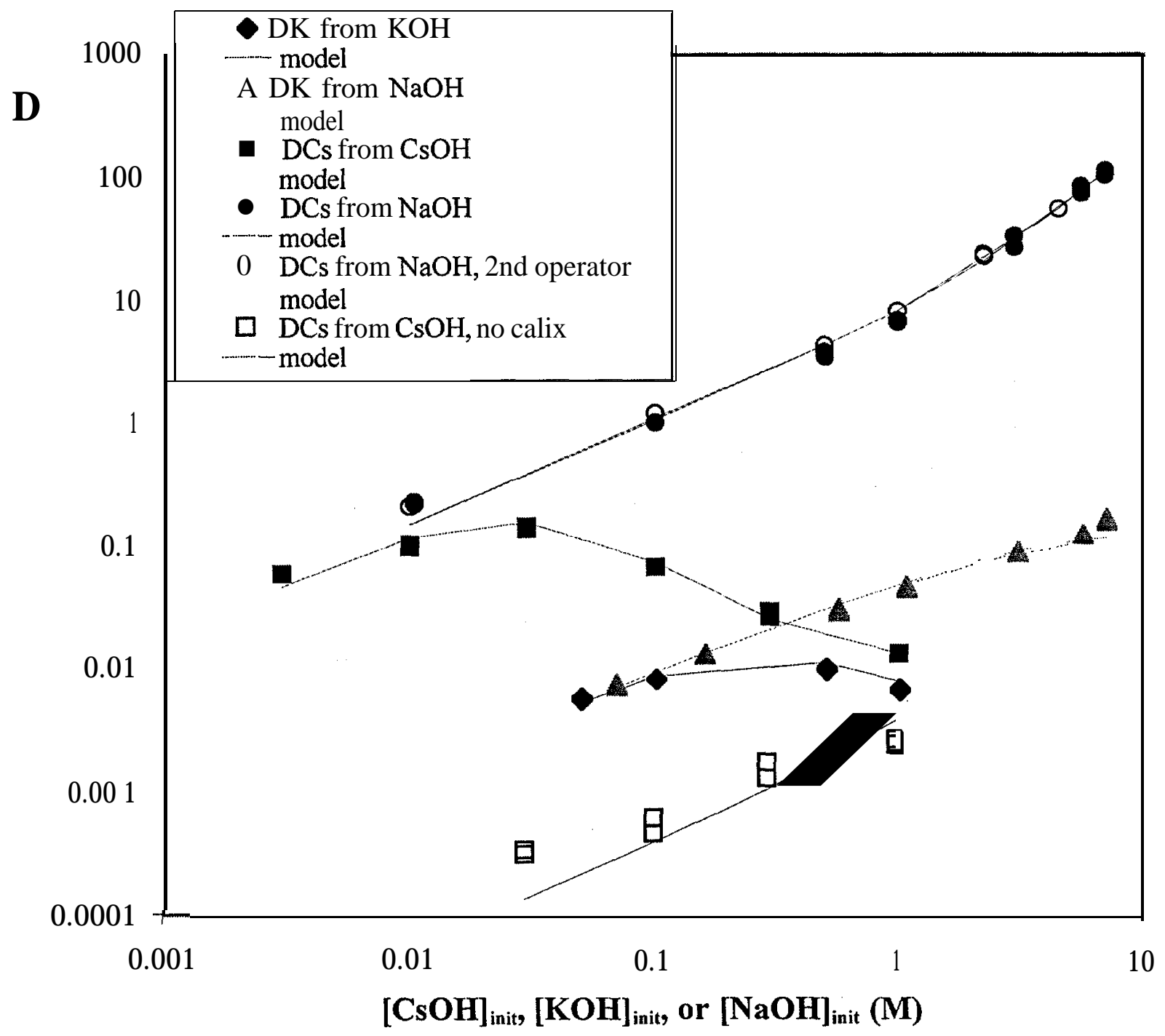

Fig. 14. M odeling of data points for hydroxide media 
The fit for all the hydroxide data is excellent, even if potassium extraction is slightly underestimated at very high concentration of sodium. This could be caused by the cation exchange between the modifier and potassium. The fit of the extraction of cesium from cesium hydroxide using a solvent that does not contain BOBCalixC6 could be better, but is satisfactory considering that the distribution ratios are low.

\subsubsection{Nitrite media}

Although not comparable in concentration to nitrate or hydroxide in the waste, nitrite is a fairly extractable anion that can play a role during the extraction of cesium from the waste. Table 7 and Figure 15 show the results obtained with this anion.

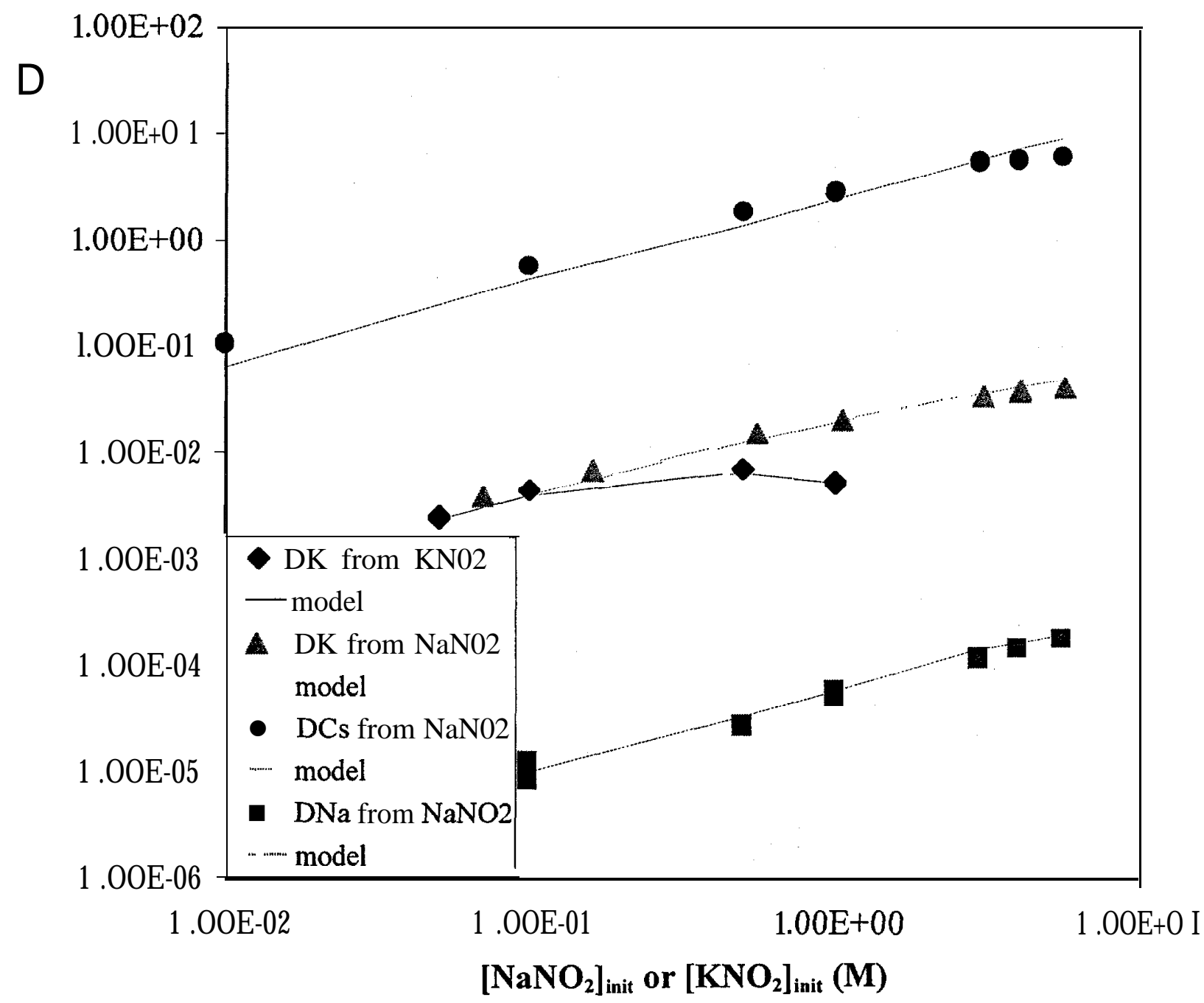

Fig. 15. M odeling of cesium and potassium distribution ratios for nitrite media 
Table 10. Species and formation constants for the model derived for nitrite data

\begin{tabular}{lc}
\hline Species & $\begin{array}{c}\text { Formation constant } \\
\text { Log:,, K }\end{array}$ \\
\hline $\mathrm{NaNO}_{2}$ Calix & $(\mathrm{o})$ \\
$\mathrm{KNO}_{2}$ Calix(o) & $0.587 \pm 0.023$ \\
$\mathrm{CsNO}_{2}$ Calix(o) & $1.121 \pm 0.025$ \\
\hline
\end{tabular}

There are no data for the extraction of cesium from cesium nitrite, as this salt was not commercially available, The behavior of the system is comparable to the behavior observed with nitrate.

\subsubsection{Chloride media}

The last major anion that was studied is chloride. This anion is among the anions that have the highest hydration energy, and therefore it is not very extractable. The formation constants of the species involving this anion are accordingly expected to be lower than those found earlier. Extraction tests showed that sodium chloride is not extracted noticeably when the calixarene is absent. Table $1 \mathrm{I}$ and Figure 16 show the cesium and potassium results obtained with this anion.

Table 11. Species and formation constants for the model derived for chloride data

\begin{tabular}{lc}
\hline Species & $\begin{array}{c}\text { Formation constant } \\
\log _{1,} \mathrm{~K}\end{array}$ \\
\hline $\mathrm{NaClCalix}_{2}(\mathrm{o})$ & $-0.132 \pm 0.027$ \\
$\mathrm{KClCalix}(\mathrm{o})$ & $0.555 \pm 0.029$ \\
$\mathrm{CsCl}(\mathrm{o})$ & $-2.03 \pm 0.31$ \\
$\mathrm{CsClCalix}(\mathrm{o})$ & $2.560 \pm 0.036$ \\
\hline
\end{tabular}




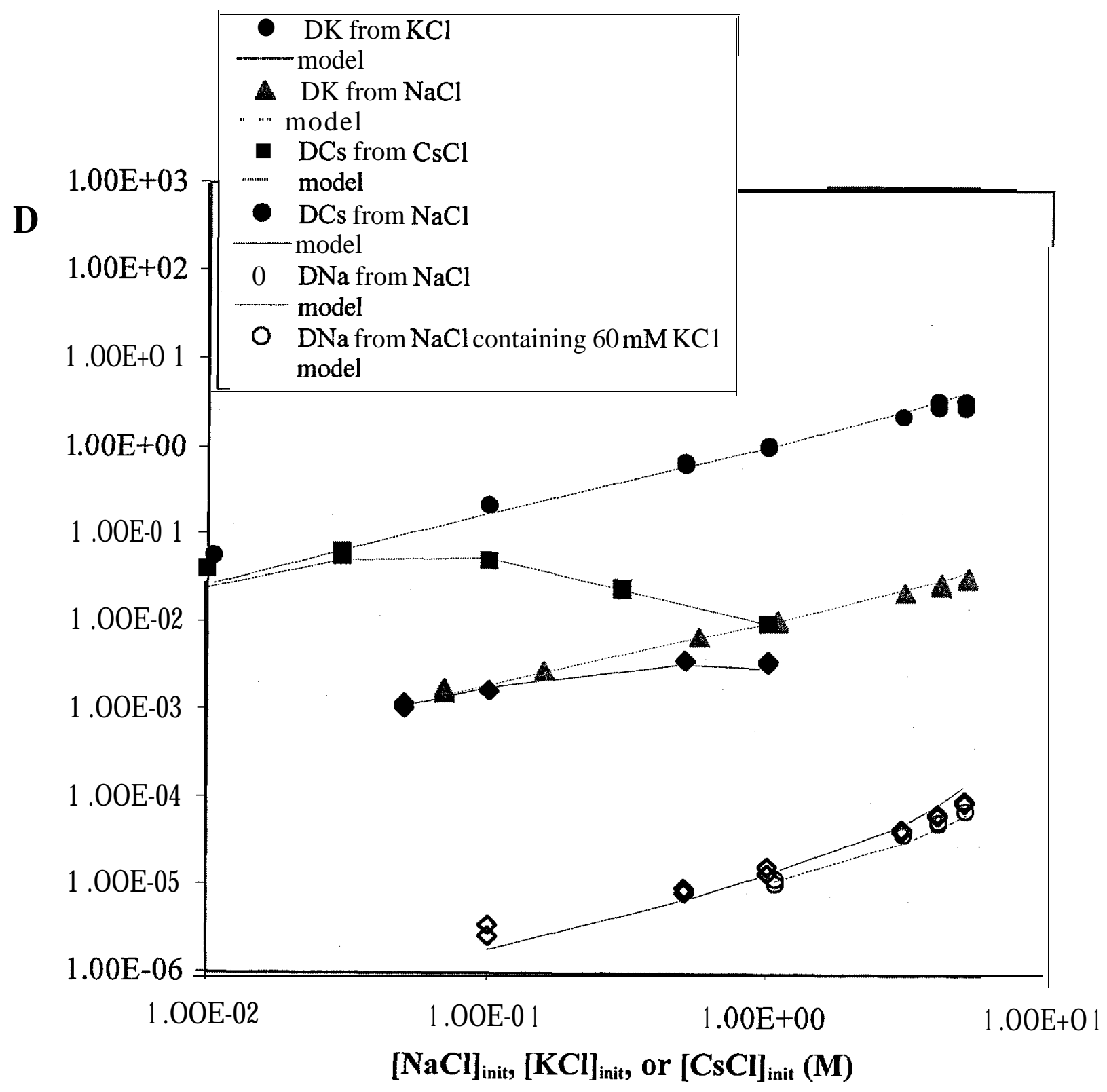

Fig. 16. M odeling of cesium and potassium distribution ratios for chloride media

\subsection{Attempt to model salt mixtures}

While all the modeling results appear satisfactory for the individual anions, it was found to be difficult to pool the species and their corresponding formation constants to predict the cesium distribution ratios obtained for mixtures of salts. When the pooled model was used, the trend shown in figures 5-9 when keeping constant the total sodium concentration and varying the relative proportion of two or more 
anions was overpredicted. It is likely that high concentrations of hydroxide result in the partial deprotonation of the modifier, which then can act as a cation exchanger. In general, the main difference between the process model and any of the more rigorous models is the sodium extraction prediction. In the process model, the extraction of cesium and potassium is well-predicted. When trying to model sodium extraction with the process model, we find that sodium extraction is overpredicted. It appears then that the loading of the calixarene is greater than what the experiments measuring the extraction of sodium provided, suggesting possibly mixed species (two extractants, two anions, sodium and cesium, for example). Most of the tests with mixtures of sodium salts were done at high ionic strengths for which mixing-effect Pitzer parameters are not available. Activity effects at high ionic strengths can play a major role and may not have been parametrized properly to the high ionic strengths attained when pooling the anion-specific models together. In addition, the solvent for the CSSX process had been defined after optimization [3] and its composition is not subject to deliberate change. For this reason along with budget and time considerations, the distribution ratios collected were obtained with this solvent so defined and none of the concentrations (TOA, modifier, and calixarene) was varied. Indeed, trioctylamine is not expected to play a major role in the extraction of the alkali cations, and fundamental extraction studies on BOBCalixC6 have shown that only one calixarene was required for cesium extraction [17]. Yet, the stoichiometry of the modifier in the different complexes is still unknown, and can be expected to be different for each anion system depending on the affinity between the modifier and the anion. A variation of the modifier concentration, and ideally of the calixarene, would bring a solid basis to the stoichiometry of the organic product species. 


\section{CONCLUSION}

A process model permitting the prediction of cesium and potassium distribution ratios from a variety of sodium salts at different concentrations has been developed. The correlation between the observed and calculated values is very good throughout all the data sets, including waste simulants. This model thus proved to be adequate for process prediction. Based on all experiments and "per anion" modeling developed for seven anions, it is reasonable to include solely species containing only nitrate, nitrite, hydroxide, and chloride in the organic phase. Modeling cesium extraction from media containing poorly extractable anions was also examined. It was determined that the impact of these anions on the system could be introduced through activity coefficients for the aqueous phase. Sulfate, carbonate, and fuoride impacts to the organic phase were demonstrated to be minor. It was also demonstrated that a more thorough model could be developed in principle, but this would require many more species (some of which are not likely encountered in process systems). 


\section{REFERENCES}

[1] H Harmon, S. Schlahta, J. Walker, D. Wester, K. Rueter, and S. Fink, Tanks Focus Area, Savannah River Site Salt Processing Project, Research and Development Program Plan, Report PNNL13253, Rev. 1, Pacific Northwest National Laboratory, Richland, Washington, Nov., 2000.

[2] L.H. Delmau, T.J. Haverlock, T.G. Levitskaia, F.V. Sloop, Jr., and B.A. Moyer, Caustic-Side Solvent Extraction Chemical and Physical Properties: Equilibrium Modeling of Distribution Behavior, Report ORNL/TM-2001/267, Oak Ridge National Laboratory, Oak Ridge, TN, December 2001.

[3] L.N. Klatt, J.F. Birdwell, Jr., P.V. Bonnesen, L.H. Delmau, L.J. Foote, D.D. Lee, R.A. Leonard, T.G. Levitskaia, M.P. Maskarinec, and B.A. Moyer, Caustic-Side Solvent Extraction SolventComposition Recommendation, Document No. CERS/SR/SX/026, Rev. 0, Nuclear Sciences and Technology Division, Oak Ridge National Laboratory, Oak Ridge, TN, November 8, 2001.

[4] C.F. Baes, Jr., W.J. McDowell, and S.A. Bryan, The Interpretation of Equilibrium Data from Synergistic Solvent Extraction systems, Solvent Extr. Ion Exch., 5, 1-28 (1987).

[5] C.F. Baes, Jr., B.A. Moyer, G.N. Case, and F.I. Case, SXLSQ A, A Computer Program for Including Both Complex Formation and Activity Effects in the Interpretation of Solvent Extraction Data, Sep. Sci. Technol., 25, 1675-1688 (1990).

[6] C.F. Baes, Jr., SX LSQ I: A Program for M odeling Solvent Extraction Systems, Oak Ridge National Laboratory Report ORNL/TM-13604, Oak Ridge National Laboratory, Oak Ridge, TN, December 1998.

[7] C.F. Baes, Jr., M odeling Solvent Extraction Systems with SXFZT, Solvent Extr. Ion Exch., 19, 193-213 (2001).

[8] F.J. Milero, in Water and Aaueous Solutions, R. A. Home, Ed., Wiley-Interscience, New York (1972).

[9] K.S. Pitzer, Activity Coefficients in Electrolyte Solutions, $2^{\text {nd }}$ ed., K.S. Pitzer, Ed., CRC Press, Boca Raton(1991).

[10] A.F.M.Barton, Halndbonla oof noetteirst and other cohesion narameters, $2^{\text {nd }}$ ed., CRC Press, Boca Raton (1983). 
[11] Handbook of Chemistry and Physics, 57 $7^{\text {th }}$ ed., R.C. Weast., Ed., CRC Press, Cleveland (1976$\left.\begin{array}{lllll}1 & 9 & 7 & 7\end{array}\right)$.

[12] R.A. Peterson, Savannah River Technology Center, Aiken, SC, private communication, Nov., 2000.

[13] D.J. Wesolowski, Aluminum speciation and equilibria in aqueous solution: I. The solubility of gibbsite in the system $\mathrm{Na}-\mathrm{K}-\mathrm{Cl}-\mathrm{OH}-\mathrm{Al}(\mathrm{OH})_{4}$ from $\mathrm{O}$ to 100 " $\mathrm{C}$, Geochimica et Cosmochimica Acta., 26, 1065-1091 (1992).

[14] A.R. Felmy, J.R. Rustad, M.J. Mason, and R. de la Bretonne, A Chemical Model for the Major Electrolyte Components of the Hanford Waste Tanks, PNNL Report TWRS-PP-99-090 (1994)

[15] P.V. Bonnesen, L.H. Delmau, T.J. Haverlock, and B.A. Moyer, Alkaline-Side Extraction of Cesium from Savannah River Tank Waste Using Calixarene-Crown Ether Extractant, Report ORNL/TM-13704, Oak Ridge National Laboratory, Oak Ridge, TN, 1998.

[16] B.A. Moyer, S.D. Alexandratos, P.V. Bonnesen, G.M. Brown, J.E. Caton, Jr, L.H. Delmau, C.R. Duchemin, T.J. Haverlock, T.G. Levitskaia, M.P. Maskarinec, F.V. Sloop, Jr., and C.L. Stine, Caustic-Side Solvent Extraction. Chemical and Physical Properties Progress in FY2000 and FY2001, Report ORNL/TM-2001/285, Oak Ridge National Laboratory, Oak Ridge, TN, February 2002.

[17] T.J. Haverlock, P.V. Bonnesen, R.A. Sachleben, and B.A. Moyer, J. Incl. Phenom. Mol. Recognit. Chem. 36, 21-37 (2000). 


\begin{abstract}
APPENDIX
This appendix shows the entire derivation of thermodynamic equations pertaining to the extraction of cesium from a system containing cesium, potassium, sodium, and a single monovalent anion $\mathrm{X}$.

The goal of this appendix is to give the reader a glimpse at the type of calculations operated by the computer program SXFIT once a set of species assumed by the modeler to be formed in the organic phase upon extraction are chosen.

The components of the system are $\mathrm{Na}^{+}, \mathrm{K}^{+}, \mathrm{Cs}^{+}, \mathrm{X}$, and a neutral organic extractant $\mathrm{B}$ (e.g. calixarene). The assumed organic species to be formed upon extraction are NaXB, KXB, and CsXB. The corresponding equilibria are:

$$
\begin{aligned}
& \mathrm{Cs}^{+}+\mathrm{X}^{-}+\overline{\mathrm{B}} \stackrel{\mathrm{K}_{\mathrm{Cs}}}{\longrightarrow} \overline{\mathrm{CsXB}} \\
& \mathrm{K}^{+}+\mathrm{X}^{-}+\overline{\mathrm{B}} \stackrel{\mathrm{K}_{\mathrm{K}}}{\longrightarrow} \mathrm{KXB} \\
& \mathrm{Na}^{+}+\mathrm{X}^{-}+\overline{\mathrm{B}} \stackrel{\mathrm{K}_{\mathrm{Na}}}{\longrightarrow} \overline{\mathrm{NaXB}}
\end{aligned}
$$

The quantity to express is $\mathbf{D}_{\mathrm{Cs}}$ as a function of the initial concentrations of components in the system and the formation constants of the product species. When using the computer program SXFIT, the formation constant values are allowed to vary so that the calculated values can match the experimental data as closely as possible. Note that in the following equations, we are using concentrations instead of activities, which is an approximation that is no longer valid at high salt concentrations but that is used here to simplify the calculations.
\end{abstract}

The formation constant equations corresponding to Equilibria 1-3 are

$$
\begin{aligned}
\mathrm{K}_{\mathrm{Cs}} & =\frac{[\overline{\mathrm{CsXB}}]}{\left[\mathrm{Cs}^{+}\right]\left[\mathrm{X}^{-}\right][\overline{\mathrm{B}}]} \\
\mathrm{K}_{\mathrm{K}} & =\frac{[\overline{\mathrm{KXB}}]}{\left[\mathrm{K}^{+}\right]\left[\mathrm{X}^{-}\right][\overline{\mathrm{B}}]} \\
\mathrm{K}_{\mathrm{Na}} & =\frac{[\overline{\mathrm{NaXB}}]}{\left[\mathrm{Na}^{+}\right]\left[\mathrm{X}^{-}\right][\overline{\mathrm{B}}]}
\end{aligned}
$$

Unless noted, all concentrations are concentrations at equilibrium, after extraction.

The expression of $D_{C s}$ can be written as a function of the equilibrium concentrations of the extractant and the anion.

$$
\mathrm{D}_{\mathrm{Cs}}=\frac{\left[\overline{\mathrm{Cs}^{+}}\right]}{\left[\mathrm{Cs}^{+}\right]}=\frac{[\overline{\mathrm{CsXB}}]}{\left[\mathrm{Cs}^{+}\right]}=\mathrm{K}_{\mathrm{Cs}}\left[\mathrm{X}^{-}\right][\overline{\mathrm{B}}]
$$


Mass-balance and charge-balance equations read as follows:

$$
\begin{aligned}
& {[\overline{\mathrm{B}}]_{\text {init }}=[\overline{\mathrm{B}}]+[\overline{\mathrm{NaXB}}]+[\overline{\mathrm{KXB}}]+[\overline{\mathrm{CsXB}}]} \\
& {\left[\mathrm{X}^{-}\right]_{\text {init }}=\left[\mathrm{X}^{-}\right]+[\overline{\mathrm{NaXB}}]+[\overline{\mathrm{KXB}}]+[\overline{\mathrm{CsXB}}]} \\
& {\left[\mathrm{Na}^{+}\right]_{\text {init }}=[\mathrm{Na}+]+[\overline{\mathrm{NaXB}}]} \\
& {\left[\mathrm{K}^{+}\right]_{\text {init }}=\left[\mathrm{K}^{+}\right]+[\overline{\mathrm{KXB}}]} \\
& {\left[\mathrm{Cs}^{+}\right]_{\text {init }}=\left[\mathrm{Cs}^{+}\right]+[\overline{\mathrm{CsXB}}]} \\
& {\left[\mathrm{X}^{-}\right]=[\mathrm{Na}+]+\left[\mathrm{K}^{+}\right]+[\mathrm{Cs}+]}
\end{aligned}
$$

Equations 8 and 9 give

$$
[\overline{\mathrm{B}}]=[\overline{\mathrm{B}}]_{\text {init }}-\left[\mathrm{X}^{-}\right]_{\text {init }}+\left[\mathrm{X}^{-}\right]
$$

Developing eq. 10 and expressing it as a function of the anion concentration, it becomes

$$
\begin{aligned}
& {\left[\mathrm{Na}^{+}\right]_{\text {init }}=[\mathrm{Na}+]+\mathrm{K}_{\mathrm{Na}}\left[\mathrm{Na}^{+}\right]\left[\mathrm{X}^{-}\right][\overline{\mathrm{B}}]=\left[\mathrm{Na}^{+}\right]\left(1+\mathrm{K}_{\mathrm{Na}}\left[\mathrm{X}^{-}\right][\overline{\mathrm{B}}]\right)} \\
& {\left[\mathrm{Na}^{+}\right]_{\text {init }}=\left[\mathrm{Na}^{+}\right]\left(1+\mathrm{K}_{\mathrm{Na}}\left[\mathrm{X}^{-}\right]\left([\overline{\mathrm{B}}]_{\text {init }}-\left[\mathrm{X}^{-}\right]_{\text {init }}+\left[\mathrm{X}^{-}\right]\right)\right)} \\
& {[\mathrm{Na}+]=\frac{\left[\mathrm{Na}^{+}\right]_{\text {init }}}{1+\mathrm{K}_{\mathrm{Na}}\left[\mathrm{X}^{-}\right]\left([\overline{\mathrm{B}}]_{\text {init }}-\left[\mathrm{X}^{-}\right]_{\text {init }}\right)+\mathrm{K}_{\mathrm{Na}}\left[\mathrm{X}^{-}\right]^{2}}}
\end{aligned}
$$

Similarly, using eq. 11 and 12

$$
\begin{aligned}
& {\left[\mathrm{K}^{+}\right]=\frac{\left[\mathrm{K}^{+}\right]_{\text {init }}}{1+\mathrm{K}_{\mathrm{K}}\left[\mathrm{X}^{-}\right]\left([\overline{\mathrm{B}}]_{\text {init }}-\left[\mathrm{X}^{-}\right]_{\text {init }}\right)+\mathrm{K}_{\mathrm{K}}\left[\mathrm{X}^{-}\right]^{2}}} \\
& {\left[\mathrm{Cs}^{+}\right]=\frac{\left[\mathrm{Cs}^{+}\right]_{\text {init }}}{1+\mathrm{K}_{\mathrm{Cs}}\left[\mathrm{X}^{-}\right]\left([\overline{\mathrm{B}}]_{\text {init }}-\left[\mathrm{X}^{-}\right]_{\text {init }}\right)+\mathrm{K}_{\mathrm{Cs}}\left[\mathrm{X}^{-}\right]^{2}}}
\end{aligned}
$$

The concentration of the anion at equilibrium can therefore be expressed solely with initial concentrations of the components of the system and the formation constants of the product species.

\section{Using again eq. 9}

$$
\left[\mathrm{X}^{-}\right]_{\text {init }}=\left[\mathrm{X}^{-}\right]+\left(\left[\mathrm{Na}^{+}\right]_{\text {init }}-\left[\mathrm{Na}^{+}\right]\right)+\left(\left[\mathrm{K}^{+}\right]_{\text {init }}-\left[\mathrm{K}^{+}\right]\right)+\left(\left[\mathrm{Cs}^{+}\right]_{\text {init }}-\left[\mathrm{Cs}^{+}\right]\right)
$$




$$
\begin{aligned}
{\left[\mathrm{X}^{-}\right]_{\text {init }}=\left[\mathrm{X}^{-}\right] } & +\left[\mathrm{Na}^{+}\right]_{\text {init }}\left(1-\frac{1}{1+\mathrm{K}_{\mathrm{Na}}\left[\mathrm{X}^{-}\right]\left([\overline{\mathrm{B}}]_{\text {init }}-\left[\mathrm{X}^{-}\right]_{\text {init }}\right)+\mathrm{K}_{\mathrm{Na}}\left[\mathrm{X}^{-}\right]^{2}}\right) \\
& +\left[\mathrm{K}^{+}\right]_{\text {init }}\left(1-\frac{1}{1+\mathrm{K}_{\mathrm{K}}\left[\mathrm{X}^{-}\right]\left([\overline{\mathrm{B}}]_{\text {init }}-\left[\mathrm{X}^{-}\right]_{\text {init }}\right)+\mathrm{K}_{\mathrm{K}}\left[\mathrm{X}^{-}\right]^{2}}\right) \\
& +\left[\mathrm{Cs}^{+}\right]_{\text {init }}\left(1-\frac{1}{1+\mathrm{K}_{\mathrm{Cs}}\left[\mathrm{X}^{-}\right]\left([\overline{\mathrm{B}}]_{\text {init }}-\left[\mathrm{X}^{-}\right]_{\text {init }}\right)+\mathrm{K}_{\mathrm{Cs}}\left[\mathrm{X}^{-}\right]^{2}}\right)
\end{aligned}
$$

The solution of this equation, where the concentration of the anion depends only on the initial concentrations and formation constants, is directly put in eq. 19. However, it is obvious that the solution of Equation 18 is not readily available as the unknown [ $\left.\mathrm{X}^{-}\right]$is present both at the numerator and the denominator and has to be solved as a seventh order polynomial equation. This equation must be solved numerically. Subsequently, eq. 19 can be resolved.

$$
\mathrm{D}_{\mathrm{Cs}}=\mathrm{K}_{\mathrm{Cs}}\left[\mathrm{X}^{-}\right][\overline{\mathrm{B}}]=\mathrm{K}_{\mathrm{Cs}}\left[\mathrm{X}^{-}\right]\left([\overline{\mathrm{B}}]_{\text {init }}-\left[\mathrm{X}^{-}\right]_{\text {init }}+\left[\mathrm{X}^{-}\right]\right)
$$

The distribution coefficient of cesium can be determined based on the initial concentrations of the components of the system and the $\mathrm{K}$ values of the species assumed to be formed upon extraction. 


\section{INTERNAL DISTRIBUTION}

1. J. F. Birdwell, Jr.

2. P. V. Bonnesen

3. D.A. Bostick

4. J. L. Collins

5. R. L. Cummins

6-8. L. H. Delmau

9. R. D. Hunt

10. T. J. Keever

11. D. D. Lee

12. T. G. Levitskaia

13. M. P. Maskarinec

14. A. J. Mattus

15. C. P. McGinnis

16. B. A. Moyer

17. F. V. Sloop, Jr.

18. R. D. Spence

19. J. F. Walker

20. J. S. Watson

21. ORNL Central Research Library

22. Laboratory Records, RC

23. Laboratory Records, OSTI

\section{EXTERNAL DISTRIBUTION}

29. S. G. Campbell, Westinghouse Savannah River Company, P.O. Box 616, Building 704-196N, Aiken, SC 29808

30. J. T. Carter, Westinghouse Savannah River Company, P.O. Box 616, Buidling 766-H, Aiken, SC 29808

31. D. Chamberlain, Argonne National Laboratory, Building 205, 9700 South Cass Avenue, Argonne, IL 60439

32. W. D. Clark, Jr., U.S. Department of Energy, Savannah River Operations Office, Building 7043N, Aiken, SC 29808

33. C. Conner, Argonne National Laboratory, Building 205, 9700 South Cass Avenue, Argonne, IL 60439 
34. R. G. Edwards, Westinghouse Savannah River Company, P.O. Box 616, Buidling 704-3N, Aiken, SC 29808

35. S. D. Fink, Westinghouse Savannah River Company, P.O. Box 616, Building 773-A, Aiken, SC 29808

36. H. D. Harmon, Tank Focus Area Salt Processing Program, P.O. Box 616, Building 704-3N, Aiken, SC 29808

37. R. T. Jones, Westinghouse Savannah River Company, P.O. Box 616, Building 704-3N, Aiken, SC 29808

38. R. A. Leonard, Argonne National Laboratory, Building 205, 9700 South Cass Avenue, Argonne, II 60439

39. R. K. Leugemors, Tank Focus Area Salt Processing Program, P.O. Box 616, Building 704-3N, Aiken, SC 29808

40. J. R. Noble-Dial, U.S. Department of Energy, Oak Ridge Operations Office, P.O. Box 2001, Oak Ridge, TN 3783 1-8620

41. Michael Norato, Westinghouse Savannah River Company, P.O. Box 616, Building 773-A, Aiken, SC 29808

42. Robert Pierce, Westinghouse Savannah River Company, P.O. Box 616, Building 773-A, Aiken, SC 29808

43. E. Saldivar, Westinghouse Savannah River Company, P.O. Box 616, Building 766H, 2027, Aiken, SC 29808

44. S. N. Schlahta, Battelle, Pacific Northwest National Lab, P.O. Box 999/ MS K9-14 Richland, WA 99352

45. P. C. Suggs, U.S. Department of Energy, Savannah River Operations Office, P.O. Box A, Building 704-3N, Aiken, SC 29808

46. W. L. Tamosaitis, Westinghouse Savannah River Company, P.O. Box 616, Building 773-A, Aiken, SC 29808 
47. M. Thompson, Westinghouse Savannah River Company, P.O. Box 616, Building 773-A, Aiken, SC 29808

48. T. A. Todd, Idaho National Engineering \& Environmental Laboratory, Building 637, MS-5218, Idaho Falls, ID 834415-5218

49. G. Vandegrift, Argonne National Laboratory, Building 205, 9700 South Cass Avenue, Argonne, IL 60439

50. D. D. Walker, Westinghouse Savannah River Company, P.O. Box 616, Building 773-A, Aiken, SC 29808

51. D. Wester, Battelle, Pacific Northwest National Lab., P.O. Box 999 / MS P7-25, Richland, WA 99352.

52. W. R. Wilmarth, Westinghouse Savannah River Company, P.O. Box 616, Building 773-A, Aiken, SC 29808

53. Tanks Focus Area Technical Team, c/o B. J. Williams, Pacific Northwest National Laboratory, P.O. Box 999, MSIN K9-69, Richland, WA 99352

54. Tanks Focus Area Field Lead, c/o T. P. Pietrok, U.S. Department of Energy, Richland Operations Office, P.O. Box 550, K8-50, Richland, WA 99352

55. Tanks Focus Area Headauarters Program Manager, c/oK. D. Gerdes, DOE Office of Science and Technology, 19901 Germantown Rd., 1154 Cloverleaf Building, Germantown, MD 20874-1290

49. Nicole Simon and Jean-François Dozol, CEA Cadarache, DESD/SEP/LPTE, Bat.326, 13108 St Paul lez Durance Cedex, France

50. Charles Madic, CEA Valrhb-Marcoule, DCC, BP 171, 30207 Bagnols s/Ceze Cedex, France 